
.

\title{
Irgm2 and Gate-16 cooperatively dampen targeting of caspase-11 to Gram-negative bacterial products
}

Elif Eren ${ }^{*}$, Rémi Planès ${ }^{1 *}$, Salimata Bagayoko ${ }^{1}$, Pierre-Jean Bordignon ${ }^{1}$, Karima Chaoui $^{1,2}$, Audrey Hessel ${ }^{1}$, Karin Santoni ${ }^{1}$, Miriam Pinilla ${ }^{1}$, Odile Burlet-Schiltz ${ }^{1,2}$, Jonathan C. Howard ${ }^{3}$, Masahiro Yamamoto ${ }^{4,5}$, Etienne Meunier ${ }^{1 \#}$

1 Institute of Pharmacology and Structural Biology (IPBS), University of Toulouse, CNRS, Toulouse; France

2 Mass spectrometry core facility, Institute of Pharmacology and Structural Biology (IPBS), University of Toulouse, CNRS, Toulouse; France

${ }^{3}$ Fundação Calouste Gulbenkian, Instituto Gulbenkian de Ciência, Oeiras; Portugal

4 Department of Immunoparasitology, Research Institute for Microbial Diseases, Osaka University, Osaka; Japan

${ }^{5}$ Laboratory of Immunoparasitology, WPI Immunology Frontier Research Center, Osaka University, Osaka; Japan

* These authors contributed equally

\# Address correspondence to: etienne.meunier@ipbs.fr (EM)

Present Address: Institute of Pharmacology and Structural Biology (IPBS), 205 Route de Narbonne, CNRS, 31000 Toulouse; France 


\section{Abstract}

Inflammatory caspase-11 (rodent) and caspases-4 and -5 (human) detect gramnegative bacterial component LPS in the host cell cytosol, which promotes activation of the non-canonical inflammasome. Although non-canonical inflammasome-induced pyroptosis and IL-1 related cytokine release is of importance to mount an efficient immune response against various bacteria, its unrestrained activation drives sepsis. This suggests that cellular components might tightly control the threshold level of the non-canonical inflammasome in order to ensure efficient but not deleterious inflammatory response. Here we show that the IFN-inducible protein Irgm2 and the ATG8 family member Gate-16 cooperatively slow down non-canonical inflammasome activation both in macrophages and in vivo. Specifically, the Irgm2/Gate-16 axis dampens caspase-11 targeting to intracellular bacteria, which lower caspase-11mediated pyroptosis and cytokine release. Specifically, deficiency in Irgm2 or Gate16 opens an alternative road for caspase-11 targeting to intracellular bacteria, independently of the classical pathway driven by the Guanylate Binding Proteins (GBPs). Thus, our findings provide new molecular effectors involved at fine-tuning the optimal non-canonical inflammasome response and add novel insights in the understanding of the immune pathways they control.

Key words:

Non-canonical inflammasome/ Caspase-11/ Irgm2/ Gate-16/ infections/ 


\section{Introduction}

Inflammasomes are cytosolic innate immune complexes that initiate inflammatory responses upon sensing of microbe- and damage- associated molecular patterns (MAMPs and DAMPs respectively) (Hayward et al, 2018). Specifically, the rodent caspase-11 (and its human orthologous Caspases-4 and -5) detects the presence of the gram-negative bacterial cell wall component lipopolysacharide (LPS) in the host cell cytosol (Hagar et al, 2013; Kayagaki et al, 2013, 2011; Yang et al, 2015; Aachoui et al, 2013; Broz et al, 2012). LPS interaction with caspase-11 caspase activation and recruitment domains (CARD) domain promotes its oligomerization and activation, which triggers the activation of the non-canonical inflammasome (Yang et al, 2015). Upon activation (Lee et al, 2018), caspase-11 cleaves and activate the pyroptosis executioner gasderminD (gsdmD) into a p30 active fragment (Shi et al, 2015; Kayagaki et al, 2015). Cleaved gsdmD then forms a pore into PIP2-enriched domains at the plasma membrane, which triggers pyroptosis, a pro-inflammatory form of cell death (Sborgi et al, 2016; Aglietti et al, 2016; Liu et al, 2016; Shi et al, 2015). In parallel, gsdmD pores-induced ionic perturbations also trigger activation of the canonical NLRP3 inflammasome, which ultimates in the caspase1-dependent maturation of the pro-inflammatory cytokines IL-1ß/IL-18 (Schmid-Burgk et al, 2015; Rühl \& Broz, 2015; Kayagaki et al, 2011). Although caspase-11 confers host protection against intracellular Gram-negative bacteria (Cerqueira et al, 2018; Chen et al, 2018; Aachoui et al, 2013), unrestrained caspase-11 response drives host pathology that includes irreversible organ failure, blood clothing and sepsis (Yang et al, 2019; Cheng et al, 2017; Napier et al, 2016; Deng et al, 2018; Yang et al, 2019; Kayagaki et al, 2011, 2013, 2015; Rathinam et al, 2019). This suggests that host regulators might fine-tune the non-canonical inflammasome in order to optimize caspase11-dependent response. So far, only few of them were described including SERPINB1-inhibited caspase-11/-4 /-1 activation in resting cells or ESCRT-mediated plasma membrane repair (Choi et al, 2019; Rühl et al, 2018).

Crucial at regulating the activation the non-canonical inflammasome pathway are the IFN-inducible GTPases, the so-called Guanylate Binding Proteins (GBPs) and the Interferon Regulated GTPase (Irg) Irgb10 (Lagrange et al, 2018; Man et al, 2016, 2015, Meunier et al, 2014, 2015; Pilla et al, 2014; Finethy et al, 2015; Zwack et al, 2017; Wallet et al, 2017; Costa Franco et al, 2018; Liu et al, 2018; Cerqueira et al, 2018). 
Specifically, GBPs (1, 2 and 5) are recruited on LPS-enriched structures such as cytosolic gram-negative bacteria and their derived products Outer Membrane Vesicles (OMVs) (Meunier et al, 2014; Finethy et al, 2017; Fisch et al, 2019; Santos et al, 2018; Lagrange et al, 2018; Man et al, 2015). Recruited GBPs then enrol caspase-11 that will bind the LPS moiety Lipid A, hence promoting the non-canonical inflammasome pathway (Fisch et al, 2019). Beyond their role at triggering GBP expression, IFNs induce more than 2000 antimicrobial genes (Green et al, 2018). Among them, many IFN-inducible regulatory genes also counter-balance over activation of the cells (Green et al, 2018). For instance, SOCS1 and USP18 are ISGs that balance the level of the host cell response (Basters et al, 2018; Liau et al, 2018). In this context, we hypothesized that IFNs, in addition to their ability to promote GBP expression, might also induce negative regulators of the non-canonical inflammasome. In this regard, Irgm proteins belong to the IFN-inducible Interferon-Related GTPases (Irgs) family proteins (Kim et al, 2012; Pilla-Moffett et al, 2016; Kim et al, 2019). Human express one IRGM protein, with various spliced variants, that is not IFN-inducible but that requires IFN signalling to be functional (Kim et al, 2019). By contrast, mice express three different Irgms, namely Irgm1, 2 and 3 (Kim et al, 2012). All Irgms lack the ability to hydrolyse the GTP due to a mutation in their catalytic domain (GMS) whereas other Irgs are GTPase active (GKS) (Coers, 2013). Although complementary processes occur, previous studies underscored an inhibitory role of $\operatorname{Irgm} 1$ and 3 on the recruitment and/or activation of the GBPs and Irg-GKS on microbial membranes (Haldar et al, 2015; Feeley et al, 2017; Haldar et al, 2013). In addition, recent studies identified Irgm1 and its human homologous IRGM, as being critical for the NLRP3 canonical inflammasome regulation by modulating the autophagy pathway, suggesting a close link between Irgm proteins and inflammasomes (pei et al, 2017; Mehto et al, 2019a, 2019b). In this context, we hypothesized that Irgms proteins might be IFNinducible controllers of the non-canonical inflammasome activation threshold.

Here, we report that IFN-inducible Irgm2 and the non-canonical autophagy effector Gate-16 cooperate to slow down non-canonical inflammasome activation by inhibiting caspase-11 targeting to intracellular bacteria. 


\section{Results} inflammasome response

IFN-inducible Irgms control Irg and GBP microbicidal activity against intracellular pathogens (Pilla-Moffett et al, 2016). In this context, we sought to determine whether Irgms might also modulate the non-canonical inflammasome response. Using an RNA interference approach (siRNA), we silenced the three murine Irgms in primary murine bone-marrow derived macrophages (BMDMs) and measured their ability to undergo into caspase-11-dependent cell death and IL-1ß maturation upon Salmonella Typhimurium challenge. To ensure that the inflammasome response in macrophages is caspase-11-dependent, we used an isogenic mutant of Salmonella (org $A^{-}$) lacking expression of SP1 encoded T3SS secretion system (Broz et al, 2012). As previously published, Casp11 and Gbp2 silencing reduced macrophage death and IL-1 $\beta$ release after 16 hours of infection (Fig 1A, EV 1A) (Meunier et al, 2014). Importantly, Irgm2silenced BMDMs died and released IL-1 $\beta$ in higher rates than control macrophages (Fig 1A, EV 1A). Such process was specific to Irgm2 as Irgm1 and 3-targeted siRNA did not induce significant variation in macrophage death and IL-1 $\beta$ release upon Salmonella $\left(\operatorname{org} A^{-}\right)$infection although mRNA levels were efficiently reduced (Fig 1A, EV 1A). To further validate that Irgm2 is a regulator of the non-canonical inflammasome response, we challenged WT, Irgm2 ${ }^{-1-}$, Casp $11^{-1-}$ and $G B P^{C h r 3-/-}$ BMDMs with a panel of gram-negative bacteria that all activate the non-canonical inflammasome. Immunoblotting experiments in WT and Irgm2-1- BMDMs showed that Irgm2 is IFN-inducible and that Irgm2 deficiency does not lead to a defect in caspase1, -11, GBP2 or GBP5 expression, all involved in the non-canonical inflammasome pathway (EV1B, C). Yet, when challenged with various gram-negative bacteria, Irgm2/- macrophages showed an exacerbated cell death, IL-1 $\beta$ release and gasdermin D p30/ caspase-1 p20 active fragments compared to their WT counterparts (Figs 1B, C). In addition, Irgm2-regulated cell pyroptosis upon gram-negative bacterial treatment was independent of NLRP3 as the use of the NLRP3 inhibitor MCC950 or N/rp3-1BMDMs did not drive any defect in cell death ( $\mathrm{LDH}$ release) while significantly reduced NLRP3-dependent IL-1 $\beta$ release (EV 1D). As expected, both Casp11 $1^{-/}$and $G B P^{C h r 3-}$

/- BMDMs were protected against gram-negative bacteria-induced non-canonical inflammasome response (Figs 1B, C). Importantly, CRISPR-deleted Irgm2 gene 


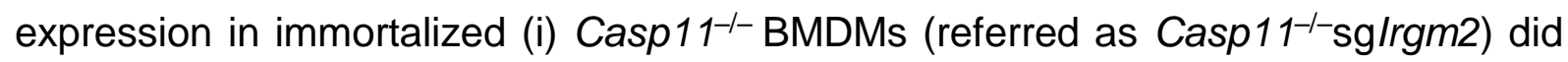
not reinduce pyroptosis and IL-1 $\beta$ release upon gram-negative bacterial infections $(S$. Typhimurium org $A^{-}$and $E$. coli) or $E$. coli-derived outer membrane vesicles (OMVs) exposure, thus confirming that Irgm2 negatively regulated caspase-11-dependent response (Fig 1D).

Then, we sought to determine whether Irgm2 also inhibited canonical inflammasomes.

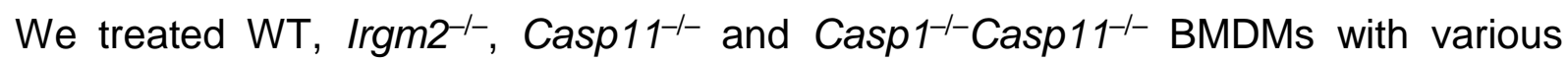
inflammasome activators, including flagellin (NLRC4), poly dAdT (AIM2), Nigericin and TcdB (NLRP3), and measured their ability to go into pyroptosis and to release IL-1 $\beta$. Although all canonical inflammasome activators induced significant caspase-1dependent response, cell death and IL-1 $\beta$ release levels remained similar in both WT and Irgm2 $^{-/-}$BMDMs (EV 1F). In addition, activation of the NLRC4 inflammasome by T3SS-expressing $P$. aeruginosa and $S$. Typhimurium remained similar between WT and Irgm2-1- BMDMs (EV 1G), suggesting that Irgm2 specifically regulates activation of the non-canonical inflammasome.

Caspase-11 is of importance at controlling intracellular gram-negative bacterial infections. Therefore, we performed a previously published model of mouse infection using the cytosolic prone strain $S$. Typhimurium lacking the virulence effector sif $A^{-}$and

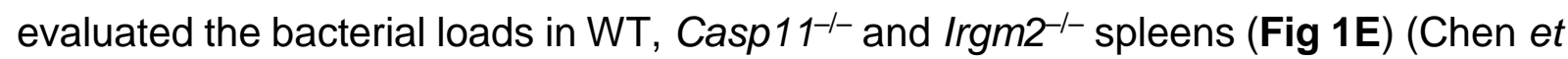
al, 2018). We observed increased bacterial loads in spleens from Casp11-1- mice compared to WT mice, which is reminiscent of the findings of Chen et al., (Chen et al, 2018). Yet, spleens from Irgm2 ${ }^{-/-}$mice had lower amount of Salmonella, thus suggesting that increased non-canonical inflammasome response in Irgm2--- mice was protective against $S$. Typhimurium sifA- infection. As Caspase-11 also drives mouse susceptibility to LPS-induced damages, we evaluated whether Irgm2 deficiency might also sensitize mice to sepsis. We used two LPS-dependent sepsis models, where WT, Irgm2 $^{-1-}$ and Casp $11^{-/-}$mice were intraperitonally injected with poly(IC) to induce ISG expression (Kayagaki et al, 2013; Santos et al, 2018). Then, mice were injected either with pure LPS $(5 \mathrm{mg} / \mathrm{kg})$ or with OMVs $(25 \mu \mathrm{g} / \mathrm{mL})$ (Santos et al, 2018; Vanaja et al, 2016). Mouse survival showed that while Casp $11^{-1-}$ mice had resistance to LPS- and OMV-induced sepsis, WT mice did succumb faster, hence validating or sepsis model (Fig 1F, G). We noticed that Irgm2 $^{-/-}$mice were even more susceptible than WT mice to both LPS- and OMV-induced sepsis (Fig 1F, G). Therefore, we used a sub-lethal 
model of OMV-induced sepsis by injecting $5 \mu \mathrm{g}$ of OMVs in mice. In such model, both WT and Casp $11^{-1-}$ mice recovered from OMV injection whereas all Irgm2 $2^{-1-}$ mice did succumb within $40 \mathrm{~h}$ post injection (Fig $\mathbf{1 H}$ ). In addition, cytokines assays showed that Irgm2 $2^{-1-}$ mice had an exacerbated release of all pro-inflammatory and inflammasomerelated cytokines tested upon OMV challenge, a phenotype that was reduced in Casp $11^{-1-}$ mice, hence confirming that Irgm2 expression is crucial to temperate the activation level of the non-canonical inflammasome (EV 1H). Altogether, our data suggest that the IFN-inducible Irgm2 specifically refrains the caspase-11 noncanonical inflammasome pathway, which protects mice to LPS-induced sepsis.

\section{Irgm2 deficiency drives GBP-independent caspase-11 targeting to gram-} negative bacterial membranes.

IFN-inducible GBPs are important regulators of the non-canonical inflammasome response. Specifically, GBPs-1 and -2 regulate human Caspase $-4 /-5$ activation while GBPs-2 and -5 control mouse caspase 11. Therefore, we hypothesized that Irgm2 might control caspase-11 response through the modulation of the GBPs. Hence, we silenced Irgm2 in WT and GBPChr3-I- BMDMs (lacking 5 GBPs, 1-3, 5 and 7) and evaluated the caspase-11 response upon OMV stimulation (EV 2A). While OMVinduced both cell death and IL-1 $\beta$ release was strongly reduced in GBPChr3-I-, Irgm2silenced GBPChr3-I- BMDMs partially recovered a caspase-11-dependent response, suggesting that Irgm2-inhibited caspase-11 response is independent of GBP modulation (Fig 2A). Other and we previously showed that GBPs also controlled canonical AIM2 inflammasome activation upon $F$. tularensis spp novicida infection. In this context, we evaluated the importance of Irgm2 at controlling AIM2 inflammasome response upon $F$. novicida infection. Surprisingly, IL-1 $\beta$ and cell death levels were not different between WT and Irgm2 ${ }^{-/-}$, although they were strongly reduced in Casp $1^{-/-}$ Casp $11^{-/-}$and $G B P^{C h r 3-/-}$ macrophages (Fig 2B, EV 2B). In addition, we observed that Irgm2-silenced GBPChr3-/- BMDMs did not recover an inflammasome response upon F. novicida infection. Then, we generated iGBPChr3-/-Irgm2 $2^{-/-}$(referred as iGBPChr3-/sglrgm2) by crispr Cas9 and evaluated their response upon $S$. Tm (orgA $)$ challenge. i/rgm2 ${ }^{-/-}$BMDMs showed time-dependent increased cell death compared to iWT cells (EV 2C, D). While, cell death in iGBPChr3-/- BMDMs was strongly impaired, it was partially reversed in iGBPChr3-/-sg/rgm2, hence suggesting that Irgm2 deficiency was 
sufficient to specifically promote caspase-11-dependent response in absence of GBPs (EV 2C, D). GBP enrichment on microbial ligand is of importance for efficient caspase11 and human caspase-4 recruitment (Thurston et al, 2016; Fisch et al, 2019). However, monitoring for GBP loading on mCherry-expressing $S$. Typhimurim did not show a significant change in the percentage of bacteria targeted by GBP2 (10-15\%) in WT and Irgm2--- BMDMs (Fig 2C).

As Caspase-11 activation needs binding to LPS, we hypothesized that Irgm2 might regulate caspase-11 recruitment to bacterial LPS. In order to monitor this, we

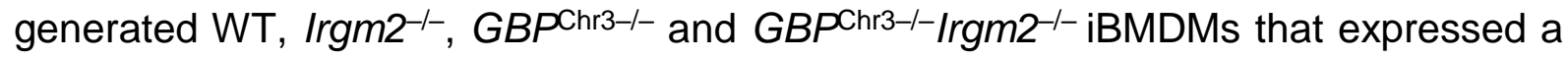
catalytically inactive mutant of caspase-11 coupled to GFP (Thurston et al, 2016) and primed them with IFNy to induce ISG expression. Observation of CASP11-C254GGFP recruitment on $S$. Typhimurium $\left(\operatorname{org} A^{-}\right)$occurred after 4 hours of infection in i/rgm2 ${ }^{-/-}$, whereas the percentage of caspase-11-targeted bacteria in iWT GBPChr3-/and $G B P^{\mathrm{Chr}-1-}$ Irgm2-1- iBMDMs remained low or null (EV 2E). Yet, after 8 hours of infection, the levels of CASP11-C254G-GFP-associated bacteria increased in iWT (10\%), albeit the percentage of CASP11-C254G-GFP+ bacteria remained below those observed in Irgm2 $^{-1-}$ cells (15-16\%) (Fig. 2D). Strikingly, we noticed that CASP11C254G-GFP targeting to Salmonella was partially restored in GBPChr3-/-Irgm2-/iBMDM after 8 hours of infection, although it was strongly impaired in GBPChr3-/- cells (Fig 2D). Altogether, our results point out that Irgm2 deficiency opens an alternative road to the GBPs for caspase-11 recruitment on bacterial membranes.

Irgm2 cooperates with GATE16 to dampen the non-canonical inflammasome activation.

As Irgm2 deficiency increased caspase-11 activation independently of GBPs, we next wondered about additional regulators. We used a GFP-Trap coupled to mass spectrometry (MS) strategy using IFNy-primed i/rgm2-1- BMDMs complemented with a doxycycline-inducible Irgm2-GFP construct (Fig 3A). We noticed that one protein was reproductively enriched in the Irgm2-GFP fraction, namely gamma-aminobutyric acid (GABA)-A-receptor-associated protein (GabarapL2 or Gate-16) (Fig 3A, EV 3A). Coimmunoprecipitation experiments confirmed that GabarapL2 was enriched in the 250 Irgm2-GFP fraction, hence validating our MS results (Fig 3B). Gabarap proteins (Gabarap, GabarapL1 and L2) belong to the ATG8 superfamily proteins, all involved in autophagy/membrane remodelling regulation. While Gabarap deficiency leads to 
increased canonical NLRP3 inflammasome response in mice, there is no information regarding the putative function of Gate-16 at regulating the non-canonical inflammasome. In this context, we found that silencing of gabarapL2 (Gate-16), but not other gabaraps, increased OMV-induced caspase-11-dependent cell death and IL-1 $\beta$ release (Fig 3C, EV 3B, C). As a control, Gate-16 silencing did not alter BMDM response to canonical NLRP3 inflammasome activators (EV 3D). Then, we sought to determine whether Gate-16-inhibited caspase-11 response was part of the Irgm2 path. Consequently, we silenced Gate-16 gene expression in WT, GBPChr3-l-, Casp $11^{-1-}$ and Irgm2 ${ }^{-1-}$ BMDMs and evaluated the ability of OMVs to induce a caspase-11-dependent response. Gate-16 silencing in WT BMDMs increased the non-canonical inflammasome response while Casp $11^{-1-}$ macrophages remained unresponsive to OMV-induced cell death, IL-1 $\beta$ release (Fig 3D). Interestingly, we observed that GBPChr3-I- macrophages silenced for Gate-16 partially recovered their ability to respond to caspase-11 activators (Fig 3E). Finally, Gate-16 knock down in Irgm2-1BMDMs did not exacerbate cell death and IL-1 $\beta$ release nor gasdermin-D or caspase1 cleavages (Fig 3D, E), suggesting that Irgm2 and Gate-16 work together to refrain non-canonical inflammasome response. As Irgm2 deficiency drives hyper caspase-11 recruitment to bacterial membranes, we wondered about the role of Gate-16 in this process. We silenced Gate-16 in iWT-expressing CASP11-C254G-GFP and checked for its recruitment on $S$. Tm membranes. Consequently, iWT BMDMs knocked down for Gate-16 had a more pronounced accumulation of caspase-11 on S. Tm membranes than the controls after 4 and 8 hours of infection (Fig 3F), which mirrored what we previously observed in Irgm2--- macrophages. To the contrary, Gate16 silencing in Irgm2 $^{-/-}$did not increase the percentage of bacteria targeted by CASP11-C254G-GFP after 4 hours of infection (EV 3E). Altogether, these results suggest that Irgm2 and Gate-16 cooperate to restrict the non-canonical inflammasome response by refraining caspase-11 targeting to bacterial membranes.

Gate-16 inhibits non-canonical inflammasome activation in human macrophages.

283 Gate-16 is expressed in both human and rodents, yet human only express one IRGM, although mice have three (Irgm1-3). Therefore, we performed siRNA-based experiments in primary human monocyte-derived macrophages (hMDMs) to determine 
whether IRGM and GATE16 might also regulate the caspase-4/5 non-canonical inflammasome. Although the use of the caspase-4/5 inhibitor LEVD and of the NLRP3 inhibitor MCC950 showed that hMDMs responded to Salmonella infection by activating the non-canonical inflammasome, we failed to observe any regulatory role for IRGM at regulating such process (Fig 4A, EV 4A). However, GATE16 silencing increased their ability to respond to Salmonella through the non-canonical inflammasome (Fig 4A, EV 4A). When we used Nigericin to trigger the canonical NLRP3 inflammasome, hMDMs knocked down for GATE16 did not show cell death and IL-1B alterations (Fig 4B). To the contrary, IRGM-silenced hMDMs had higher IL-1B and cell death levels than their respective controls, which is reminiscent of previous studies that showed a regulatory role for IRGM on the canonical NLRP3 inflammasome (Fig 4B). Although, the research of a protein with a similar function of rodent Irgm2 in human warrants further investigations, our results suggest that GATE16 function is conserved between both species. Altogether, our results identified two novel regulators, namely Irgm2 and GATE16 that cooperatively restrict the non-canonical inflammasome in both mice and humans. This suggests that the Irgm2/Gate-16 axis is part of a novel regulatory path that fine-tunes the non-canonical inflammasome threshold level. 


\section{Discussion}

Activation of the non-canonical inflammasome is of major importance at triggering an inflammatory response upon gram-negative bacterial challenge. However, uncontrolled non-canonical inflammasome response drives endotoxic shock, which suggests that host factors might tightly regulate the non-canonical inflammasome at various steps. Conversely, two recent studies have uncovered that the IRF2 transcription factor (and to a lower extend IRF1) transcriptionally control murine gasdermin D and human caspase-4 expression (Kayagaki et al, 2019; Benaoudia et al, 2019). In addition, SERPINB1 has also been found to directly interact and inhibit activation of the inflammatory caspases-1, -4 , and -11 (Choi et al, 2019). Here we report a critical role of Irgm2 and Gate-16 at balancing the non-canonical inflammasome activity. The Irgm2/Gate-16 axis was required to inhibit caspase-11 recruitment to the gram-negative bacterial product LPS in the host cell cytosol, which provided controlled caspase-11 response and protection against sepsis. While this manuscript was submitted, the group of $\mathrm{J}$ Coers also described the regulation of the caspase-11 non-canonical inflammasome by the Irgm2 axis. These findings open many yet unanswered questions such as at which step the Irgm2/Gate16 axis is regulating caspase- 11 recruitment to bacterial products. Gate-16 has been found to control proper cytosolic localization of various GBPs (Park et al, 2016; Sasai et al, 2017), including GBP2, crucial at regulating caspase-11 recruitment on intracellular pathogen PAMPs. However, our results indicate that Gate16/Irgm2 removal in GBPdeficient macrophages reinsures caspase-11-dependent response, which suggests that the Gate-16/Irgm2 path might regulate caspase-11, at least to certain extend, independently of the GBPs. So far, due to the lack of information, a possible function of Irgm2 remains elusive, but Irgm1 and its human homologous IRGM have been described to participate in the autophagy/xenophagy processes (Azzam et al, 2017; Maric-Biresev et al, 2016). In addition, Gate-16 belongs to the ATG8-like proteins, including LC3 (abc), Gabarap and GabarapL1, all involved in various autophagy/membrane remodelling step regulation such as lysosome biogenesis, autophagosome formation and closure (Nguyen et al, 2016; Gu et al, 2019; Lee \& Lee, 2016). To this regard, both Irgm1/IRGM and Gabarap proteins inhibit activation of the canonical NIrp3 inflammasome (pei et al, 2017; Mehto et al, 2019b, 2019a). Therefore, one can hypothesizes that Gate-16 and Irgm2 deficiencies could lead to defective 
autophagy, which would promote cytosolic LPS accumulation and an exacerbated caspase-11 activation. Therefore, experiments using various genetically invalidated cells for autophagy components such as ATG4b, responsible of ATG8 family protein maturations status, might help at determining the importance of the autophagy machinery on Irgm2/Gate-16 axis-inhibited caspase-11 response. Another possible explanation relies on the Golgi enrichment of both Irgm2 and Gate-16 (Sagiv, 2000; Zhao et al, 2010). Indeed, Gate-16 also regulates Snare-dependent vesicular trafficking, independently of its autophagy function (Sagiv, 2000). Various groups previously found that endocytosed and intracellular monomeric LPS could be targeted to the Golgi apparatus (Latz et al, 2002; Thieblemont \& Wright, 1999). Caspase-4, 5 and 11 need accessible lipid $A$ to oligomerize and auto activate, which can be extremely difficult in presence of multimeric and hydrophobic LPS particles to the contrary of monomeric LPS that might present a more accessible lipid A. An attractive hypothesis is that GBP-mediated bacterial membrane damages allow LPS retrieval from aggregates in order to ensure proper lipid A exposure to caspase-11 (Santos et al, 2018). Therefore, one could speculate that Golgi-regulated monomeric LPS trafficking might be impaired in absence of either Irgm2 or Gate-16, which would allow direct caspase-11/lipid A interactions without the need for GBPs.

Another standing question lies on the hierarchical involvement of Irgm2 and Gate-16 at regulating the non-canonical inflammasome response. Although our results suggest that both proteins are part of the same pathway, their respective contribution at inhibiting LPS-induced caspase-11 activation remains elusive. Due to the strong response of Irgm2-silenced BMDMs compared to Gate-16 knock down, it is tempting to put Irgm2 as an upstream regulator of Gate-16, which suggests that additional partners/effectors might be involved downstream of Irgm2. In this context, gate16 pull down coupled to mass spectrometry experiments might help identifying additional regulators of the non-canonical inflammasome response.

Our results showed that both murine and human Gate-16 regulate the non-canonical inflammasome response to LPS-containing particles. Yet, we failed to isolate IRGM as a human functional homologous of Irgm2. Given the strong role of Irgm2 at regulating the non-canonical inflammasome in mice, there is a possibility that another, yet unidentified, human protein holds a similar function of the one carried out by Irgm2. Therefore, this warrants future investigations to identify such Irgm2-like human protein. 
381 Human and mice have different sensitivities to LPS. Indeed, LPS-induced sepsis in 382 mice requires 1-25 mg/kg of LPS whereas humans have a 100-1 000000 time lower 383 sepsis threshold (2-4 ng/kg of LPS) (Fink, 2014). Another explanation could be that 384 the evolutionary loss of Irgm2 in humans would leave human cells with only Gate-16, 385 which would greatly lower the sensitivity of human cells to cytosolic LPS-activated non386 canonical inflammasome.

387 In summary, our work identified two negative regulators of caspase-11 recruitment to 388 bacterial membranes, namely Irgm2 and Gate-16. Additional investigations will be 389 necessary to understand how both effectors balance caspases $-4,-5$ and -11 sensitivity 390 to intracellular LPS, and what specific physiological and cellular processes Irgm2 and 391 Gate-16 cover together. 


\section{Method}

409

Reagents, biological samples and their concentration of use are referenced in the Appendix table 1

\section{Mice}

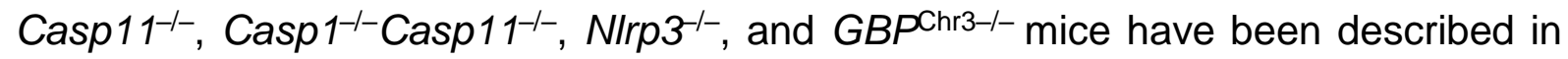
previous (Yamamoto et al, 2012; Martinon et al, 2006; Li et al, 1995; Wang et al, 1998). Irgm2 $^{-1-}$ mice provided from the Jackson laboratory (USA). All mice were bred at the IPBS institute (Toulouse, France) animal facilities according to the EU and French directives on animal welfare (Directive 2010/63/EU). Charles Rivers provided WT C57B6 mice.

\section{Animal sepsis models}

8-12 weeks old mice (sex-matched, 6-10 per group) were injected intraperitoneally with

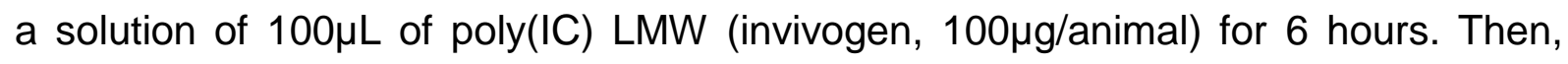
$5 \mathrm{mg} / \mathrm{kg}$ of LPS (Invivogen, O111:B4) or 5 or $25 \mu \mathrm{g} /$ animal of outer membrane vesicles (E. coli, Invivogen) were intraperitoneally injected. Mice survival was monitored over 80 hours. For cytokine assays, poly (IC)-primed mice were injected with $25 \mu \mathrm{g} /$ animal of OMVs for 8 hours and plasma cytokines amounts were addressed using ELISA kits (listed in the Appendix Table 1). There were no randomization or blinding performed.

Animal experiments were approved (License APAFIS\#8521-2017041008135771, Minister of Research, France) and performed according to local guidelines (French ethical laws) and the European Union animal protection directive (Directive 2010/63/EU).

\section{Animal infection}

6-10 mice/group were intraperitoneally infected with $5.10^{5}$ CFUs of stationary phase Salmonella sifA- strain. Animals were sacrificed 48 hours after infection. Spleen bacterial loads were evaluated using CFU plating and plasma cytokine levels were determined using ELISA kits. There were no randomization or blinding performed. 


\section{BMDM isolation and culture.}

Murine Bone Marrow-Derived Macrophages (BMDMs) generation has previously been described. Briefly, bone marrow progenitors were differentiated in DMEM (Invitrogen) supplemented with 10\% v/v FCS (Thermo Fisher Scientific), 10\% v/v MCSF (L929 cell supernatant), $10 \mathrm{mM} \mathrm{HEPES} \mathrm{(Invitrogen),} \mathrm{and} \mathrm{nonessential} \mathrm{amino} \mathrm{acids} \mathrm{(Invitrogen)}$ for 7 days. For experiments, $1.25 \times 10^{6}, 2.5 \times 10^{5}$, or $5 \times 10^{4}$ BMDMs were seeded in 6-, 24-, or 96-well-plates, respectively. When described BMDMs were pre-stimulated overnight with either PAM3CSK4 (InvivoGen, $100 \mathrm{ng} / \mathrm{mL}$ ) or IFN- $\gamma$ (PeProtech, $100 \mathrm{UI} / \mathrm{mL}$ ). For non-canonical inflammasome stimulation, we used pure LPS (O111B4, Invivogen, $1 \mu \mathrm{g} / \mathrm{mL}$ ), Outer Membrane Vesicles (E. coli, Invivogen, 0.5, 1 and 2.5 $\mu \mathrm{g} / 2.10^{5}$ cells) or various gram-negative bacterial strains were used including, Shigella flexneri (M90T, MOI25), Salmonella Typhimurium orgA- (SL1344, MOI25), E. coli (K12, MOI25), C. koseri (MOI25), E. cloacae (MOI25).

For canonical inflammasome stimulations, over-night (ON) IFNy-primed BMDMs were then prestimulated with PAM3CSK4 (InvivoGen, $100 \mathrm{ng} / \mathrm{mL}$ ) for 4hours to induce pro-

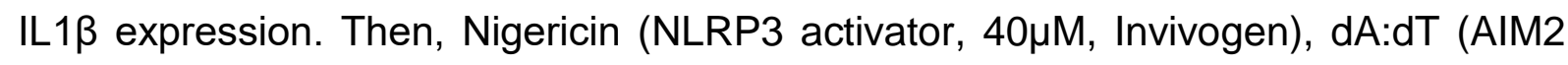
activator, $1 \mu \mathrm{g} / \mathrm{mL}$, Invivogen), TcdB toxin (PYRIN inducer, $0.05 \mu \mathrm{g} / \mathrm{mL}$, List Biological Laboratories) or flagellin (NLRC4 trigger, $1 \mu \mathrm{g} / \mathrm{mL}$, Invivogen) were used to stimulate various canonical inflammasomes. Both flagellin and poly (dA:dT) were transfected into cells using FuGeneHD (Promega) transfection reagent in Opti-MEM culture medium. When specified $P$. aeruginosa (PAO1) and $S$. Tm strains (MOI 5) were used to trigger NLRC4 inflammasome response.

For all stimulations, macrophages medium was replaced by serum-free and antibioticfree Opti-MEM medium and inflammasome triggers were added to the macrophages for various times.

Specific to infections, plates were centrifuged for 1 minute, $800 \mathrm{rpm}$ to ensure homogenous infections. Then, extracellular bacteria were eliminated with gentamicin (100 $\mu \mathrm{g} / \mathrm{ml}$, Invitrogen). 


\section{Bacterial cultures}

469

470

471

472

473

474

475

476

477

478

479

480

481

482

483

484

485

486

487

488

489

490

491

492

493

494

495

496

497

bacteria were grown overnight in Luria Broth (LB) medium at $37^{\circ} \mathrm{C}$ with aeration and constant agitation in the presence or absence of antibiotics (specified in the Appendix table 1). Stationary phase (OD of 2-2.5) bacteria when then used for infections. Stimulation of the NLRC4 inflammasome by $S$. Typhimurium SL1344 and $P$. aeruginosa PAO1 bacteria required proper T3SS and flagellin expression; therefore bacteria were sub-cultured the next day by dilution overnight culture 1/50 and grew until reaching an O.D600 of $0.6-1$

\section{Gene knock down.}

Gene silencing was achieved using siRNA pools (Dharmacon, 25nM/well listed in table S1) as previously described (Santos et al, 2018; Meunier et al, 2015) or accell siRNA technology. SiRNA smart pools from Dharmacon were transfected into cells using the DharmaFECT 4 transfection reagent (Dharmacon) for 48 hours. Primary Human macrophages were treated with $1 \mu \mathrm{M}$ siRNA Accell (Dharmacon, smart pool) in absence of transfection reagent for 72 hours. Then, murine BMDMs and human macrophages were stimulated with $1 \mu \mathrm{g} / 2.10^{5}$ cells of OMVs or infected with Salmonella Typhimurium ( $\operatorname{org} A^{-}$) to trigger non-canonical inflammasome response. For siRNA experiments, gene knockdown efficiency was monitored by qRTPCR or immunoblotting (WB) assays.

\section{Quantitative Real Time PCR.}

Cellular RNA were extracted from $2.510^{5}$ cells using RNeasy Mini Kit (Qiagen). mRNAs were reverse transcribed with the Verso cDNA Synthesis Kit (ThermoScientific). Regarding qPCR experiments, $1 \mu \mathrm{M}$ of primers (Appendix Table S1), SYBR ${ }^{\text {TM }}$ Select Master Mix (ThermoScientific) and 15ng of cDNA were mixed in a $10 \mu \mathrm{L}$ reaction in a QuantStudio 5 device (Applied Biosystems). Primers were generated using primer3 software. 


\section{Cytokine and pyroptosis measurement}

499

500

501

502

503

504

505

506

507

508

509

510

511

512

513

514

515

516

517

518

519

520

521

522

523

524

525

526

527

528

Murine II-1 $\alpha$, IL-1 $\beta$, TNFa, IL12, IL18, IFNy, IL-6 and human IL-1B cytokine levels were measured by ELISA (listed in appendix table 1). LDH Cytotoxicity Detection Kit (Takara) allowed to monitore for cell lysis. Normalization of spontaneous lysis was calculated as follows: (LDH infected - LDH uninfected)/(LDH total lysis - LDH uninfected) ${ }^{*} 100$.

\section{Immunoblotting}

Preparation of cell lysates and supernatants have been described previously. Proteins were loaded and separated in 12\% SDS-PAGE gels and then transferred on PVDF membranes. After 1 hour of saturation in Tris-buffered saline (TBS) with $0.05 \%$ Tween 20 containing 5\% non-fat milk ( $\mathrm{pH} 8)$, membranes were incubated overnight with various antibodies (referenced in table 1). The next day, membranes were washed 3 times in TBS $0.1 \%$ Tween 20 and incubated with appropriate secondary horseradish peroxidase (HRP)-conjugated antibody (dilution 1/5000-10000, listed in Appendix table 1) for $1 \mathrm{~h}$ at room temperature. Then, after 3 washes, immunoblottings were revealed with a chemiluminescent substrate ECL substrate (Biorad) and images were acquired using ChemiDoc Imaging System (Biorad). All antibody references and working dilutions are presented in Appendix table 1.

\section{Microscopy}

$2.5 \times 10^{5}$ BMDMs on glass coverslips were infected with $S$. Typhimurium (MOI10) expressing an mCherry fluorescent protein. At the indicated times, cells were washed three times with PBS and fixed with $4 \%$ PFA for 10 minutes at $37^{\circ} \mathrm{C} .0,1 \mathrm{M}$ Glycine was used to quench excess of PFA for $10 \mathrm{~min}$ at room temperature. Then cells were permeabilized and incubated with primary antibodies $\mathrm{O} / \mathrm{N}$ at $4^{\circ} \mathrm{C}$ in Saponin $0.1 \% / B S A$ $3 \%$ solution. Cellular stainings were achieved using Hoescht (DNA labeling), GBP2 antibody (gift from J Howard). Coverslips were then washed with Saponin/BSA solution and further incubated with the appropriate secondary antibodies coupled to fluorochromes (1/1000, appendix table 1). After 3 washes with PBS, cells were mounted on glass slides using Vectashield (Vectalabs). Coverslips were imaged using 
confocal Zeiss LSM 710 (Image core Facility, IPBS, Toulouse or an Olympus/Andor CSU-X1 Spinning disk microscope using a 63x oil objective. Otherwise specified, 5-10 fields /experiment were manually counted using Image $\mathrm{J}$ software.

\section{Transduction of iBMDMs}

HEK 293-based retroviral packaging cell line (GP2-293) were plated in $10 \mathrm{~cm}$ petri dish in DMEM $+10 \%$ FCS $+1 \%$ PS. When cell's confluency reached $60-80 \%$, cells were placed in serum and antibiotics-free Opti-mem medium and transfected with VSV-G encoding vector (pMD.2G) along with CASP11-C254G-GFP or pRetro (-GFP or Irgm2-GFP) vectors using PEI transfection reagent. $10 \mathrm{hrs}$ after transfection cell medium was replaced by DMEM $+10 \%$ FCS $+1 \%$ PS. At 48 hrs post-transfection cell's supernatant containing retroviral particles were collected, filtered $0.45 \mu \mathrm{m}$ and used to transduce target cells. After 48 hours, puromycin $(5 \mu \mathrm{g} / \mathrm{mL})$ was used to select cells positively transduced with the transgene. When vectors contained GFP fusions, cells were sorted using Fluorescence-Activated Cell Sorting.

\section{Immunoprecipitation and GFP Trap.}

Irgm2 ${ }^{-1-}$ immortalized macrophages were transduced with retroviral vectors carrying a doxycycline inducible Irgm2-GFP, or GFP alone constructs, cloned into Retro-X ${ }^{\mathrm{TM}}$ Tet$\mathrm{On} \circledast 3 \mathrm{G}$ vector (Clontech Laboratories, Inc.). To ensure proper Irgm2-GFP expression cells were incubated $16 \mathrm{hrs}$ with doxycycline $1 \mu \mathrm{g} / \mathrm{ml}$ in presence of IFNy. Irgm2-GFP and associated protein complexes were pull-down using GFP-Trap magnetic beads according to manufacturer's instructions (chromotek). Briefly, cells were lysed in ColP lysis buffer (10 mM Tris/Cl pH7.5; $150 \mathrm{mM} \mathrm{NaCl}$; 0.5mM EDTA; 0.5\% NP40, 0.09\% Na-Azide) supplemented with a protease inhibitor cocktail (Roche). Cell lysates were then incubated with GFP-Trap-MA beads for $1 \mathrm{hr}$ at $4^{\circ} \mathrm{C}$. After 2 washes with washbuffer (10 mM Tris/Cl pH 7.5; 150 mM NaCl; 0.5 mM EDTA, 0.018\% Na-Azide) GFPTrap complexes were boiled for $10 \mathrm{~min}$ at $95^{\circ} \mathrm{C}$ in RIPA buffer + laemli before separation on SDS-PAGE and mass spectrometry or immunoblotting. 


\section{Mass spectrometry analysis}

561

562

563

564

565

566

567

568

569

570

571

572

573

574

575

576

577

578

579

580

581

582

583

584

585

586

587

588

589

590

591

Immunopurified protein samples were reduced with $\beta$-Mercaptoethanol by heating at $95^{\circ} \mathrm{C}$ for $5 \mathrm{~min}$, and cysteines were alkylated by addition of $90 \mathrm{mM}$ iodoacetamide. Samples were loaded on a 1D SDS-PAGE gel and proteins were isolated in a single gel band, which was excised and washed with several cycles of $50 \mathrm{mM}$ ammonium bicarbonate-acetonitrile (1:1). Proteins were in-gel digested using $0.6 \mu \mathrm{g}$ of modified sequencing grade trypsin (Promega) in $50 \mathrm{mM}$ ammonium bicarbonate overnight at $37^{\circ} \mathrm{C}$. Resulting peptides were extracted from the gel by successive incubations in 50 $\mathrm{mM}$ ammonium bicarbonate and 10\% formic acid-acetonitrile (1:1), then dried in a speed-vac, and resuspended with $22 \mu \mathrm{L}$ of $5 \%$ acetonitrile, $0.05 \%$ trifluoroacetic acid (TFA) for MS analysis. Peptides were analyzed by nanoLC-MS/MS using an UltiMate Nano/Cap System NCS-3500RS coupled to a Q-Exactive HFX mass spectrometer (Thermo Fisher Scientific, Bremen, Germany). Separation was performed on a C-18 column (75 $\mathrm{m}$ ID $\times 50 \mathrm{~cm}$, Reprosil C18) equilibrated in $95 \%$ solvent $A(5 \%$ acetonitrile, $0.2 \%$ formic acid) and $5 \%$ solvent $B(80 \%$ acetonitrile, $0.2 \%$ formic acid), using a gradient from 10 to $45 \%$ gradient of solvent B over 60 min at a flow rate of 350 $\mathrm{nL} / \mathrm{min}$. The mass spectrometer was operated in data-dependent acquisition mode with the Xcalibur software. Survey MS scans were acquired in the Orbitrap on the 350$1400 \mathrm{~m} / \mathrm{z}$ range, with the resolution set to 60,000 , and the 12 most intense ions were selected for fragmentation by Higher-energy Collisional Dissociation (HCD) using a normalized collision energy of 28. MS/MS scans were collected at 15,000 resolution with an AGC target value of $1 \mathrm{e} 5$ and a maximum injection time of $22 \mathrm{~ms}$. Dynamic exclusion was used within $30 \mathrm{~s}$ to prevent repetitive selection of the same peptide. Three replicate MS analysis were performed for each sample.

\section{Bioinformatic processing of mass spectrometry data}

Raw mass spectrometry files were searched using Mascot (Matrix Science) against the Mouse entries of the Swissprot-TrEmbl protein database. The enzyme specificity was "trypsin", with a maximum of 2 misscleavages. Cysteine carbamidomethylation was set as a fixed modification, and $\mathrm{N}$-terminal protein acetylation and methionine oxidation were specified as variable modifications. For the search, mass tolerance parameters were set at $5 \mathrm{ppm}$ on the parent ion and $20 \mathrm{mmu}$ on the fragment ions. 
592 Protein identification results were then validated with the Proline software by the target-

593 decoy approach using a reverse database at a both a peptide and protein FDR of $1 \%$.

594 To perform label-free relative quantification of proteins, the "abudance" metric retrieved

595 by Proline was used, after global normalization of the MS signal across all MS runs.

596 For each protein, a mean abundance value was computed from technical LC-MS

597 replicate runs, and log2-transformed. Missing protein abundance values were then

598 replaced by a noise value estimated for each analysis as the $1 \%$ lowest percentile of

599 the protein abundance values distribution. Bona fide Irgm2 interactors were identified

600 by comparing Irmg2-GFP immuno-purified samples and GFP control samples. For

each protein, an enrichment ratio relative to the control and a Student t-test $p$-value were calculated from the protein abundance values derived from 3 independent biological replicate experiments. Relevant interactors were selected based on an enrichment ratio higher than 2 and a Student t-test $p$-value lower than 0.05 .

\section{Genetic invalidation of Caspase11 and Irgm2 genes in immortalized BMDMs}

607 Casp11 and Irgm2 genes were knocked-out using the crispr/cas9 system in onco J2immortalized (i) bone-marrow derived macrophages (BMDMs) iWTs or ilrgm2 $2^{-/}$ macrophages. Single guide RNAs (sgRNA) specifically targeting Caspase-11 exon 2 forward

(5‘CACCGCTTAAGGTGTTGGAACAGCT3’)

reverse

exon

2 forward (Benchling.com), and oligonucleotides were synthesized by Sigma-Aldrich. Crispr guide RNA oligonucleotides were then hybridized and cloned in Lenti-gRNAPuromycin vector using BsmBI restriction enzyme (lentiGuide-Puro, Addgene 52963, Feng Zhang lab). HEK293T cells were transfected for 48 hours with all constructs (lipofectamine 2000) together with the lentiviral packaging vector p8.91 (Didier Trono lab, EPFL, Switzerland) and the envelop coding VSVg plasmid (pMD.2G, Addgene 12259, Didier Trono lab). 48 hours later, viral supernatants were harvested and subsequently filtered on $0.45 \mu \mathrm{m}$ filter. Recipient cells expressing Cas9 $(1,000,000$ cells/well in 6-well plates) were generated using lentiviral transduction with a Cas9- 
viral particles were centrifugated for $2 \mathrm{~h}$ at $2900 \mathrm{rpm}$ at $32^{\circ} \mathrm{C}$ in presence of $8 \mu \mathrm{g} / \mathrm{ml}$ polybrene. $48 \mathrm{~h}$ later, medium was replaced and Puromycin selection $(10 \mu \mathrm{g} / \mathrm{mL})$ was applied to select positive clones for two weeks. Puromycin-resistant cells were sorted at the single cell level by FACS (Aria cell sorter). Individual clones were subjected to western blotting to confirm the absence of targeted proteins.

\section{Generation of human monocyte-derived Macrophages}

Peripheral Blood Mononuclear Cells (PBMCs) were isolated from buffy coat of healthy donors obtained from the EFS Toulouse Purpan (France) as described previously (ref). Briefly, PBMCs were isolated by centrifugation using standard Ficoll-Paque density (GE Healthcare). The blood was diluted 1:1 in phosphate-buffered saline (PBS) prewarmed to $37^{\circ} \mathrm{C}$ and carefully layered over the Ficoll-Paque gradient. The tubes were centrifuged for $25 \mathrm{~min}$ at $2000 \mathrm{rpm}$, at $20^{\circ} \mathrm{C}$. The cell interface layer was harvested carefully, and the cells were washed twice in PBS (for $10 \mathrm{~min}$ at $1200 \mathrm{rpm}$ followed by 10 min at $800 \mathrm{rpm}$ ) and re-suspended in RPMI-1640 supplemented with $10 \%$ of foetal calf serum (FCS), $1 \%$ penicillin $(100 \mathrm{IU} / \mathrm{mL})$ and streptomycin $(100 \mu \mathrm{g} / \mathrm{ml})$. Monocytes were separated from lymphocytes by positive selection using CD14+ isolation kit (Myltenyi biotec). To allow differentiation into monocyte-derived macrophages, cells were cultured in RPMI medium (GIBCO) supplemented with 10\% FCS (Invitrogen), $100 \mathrm{IU} / \mathrm{ml}$ penicillin, $100 \mu \mathrm{g} / \mathrm{ml}$ streptomycin, $10 \mathrm{ng} / \mathrm{ml}$ M-CSF for 7 days.

\section{Ethics statements}

The use of human cells was approved by the Research Ethical Committee, HauteGaronne, France. Buffy coats were provided anonymously by the EFS (établissement français du sang, Toulouse, France). Written informed consent was obtained from each donor under EFS contract $n^{\circ}$ 21PLER2017-0035AV02, according, to "Decret $\mathrm{N}^{\circ}$ 2007-1220 (articles L1243-4, R1243-61)". 


\section{Statistical analysis}

656 Statistical data analysis was performed using Prism 5.0a (GraphPad Software, Inc.).

657 T-test with Bonferroni correction was used for comparison of two groups. For multiple

658 comparisons, One-Way ANOVA with Multiple Bonferroni correction test was used.

659 Data are reported as mean with SEM. For animal experiments Mann-Whitney tests

660 were performed and for mouse survival analysis log-rank Cox-Mantel test was

661 selected. $P$ values are given in figures, NS means non-significant. Significance is

662 specified as ${ }^{*} p \leq 0.05 ;{ }^{* *} p \leq 0.01,{ }^{* * *} p \leq 0.001$.

663

664

665

666

667

668

669

670

671

672

673

674

675

676

677

678

679

680 
681

682

683

684

685

686

687

688

689

690

691

692

693

694

695

696

697

698

699

700

701

702

703

704

705

706

707

708

709

710

711

\section{ACKNOWLEDGEMENTS}

We would like to acknowledge Jonathan Howard for anti-Irgm2 anti-serum and antiGBP2 as well as Biotem company for generating anti-Irgm2 antibodies; Junying Yuan (Harvard Med School, Boston, USA) and B. Py (CIRI institute, Lyon, France) for

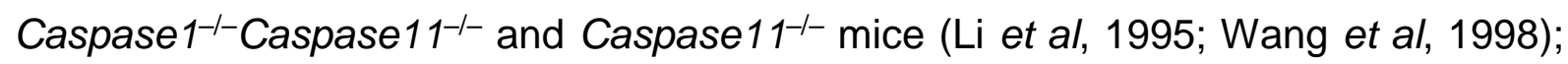
M. Yamamoto (Osaka University, Japan) for GBPChr3-/- mice (Yamamoto et al, 2012),

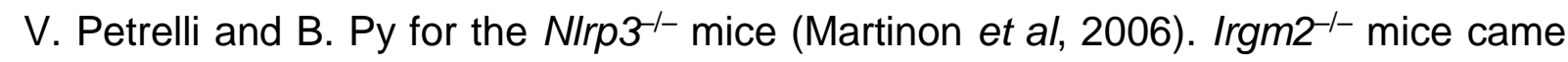
from the Jackson laboratory. Authors also acknowledge the animal facility, mass spectrometry and microscopy platforms of the IPBS institute. We specifically acknowledge Drs. C. Cougoule and Y. Rombouts for fruitful discussions and suggestions as well as for reading and implementing the MS. This project was funded by grants from FRM "Amorçage Jeunes Equipes" (AJE20151034460), ERC StG (INFLAME 804249) and ATIP to EM and from the European Society of Clinical Microbiology and Infectious Diseases (ESCMID, 2020) to RP. MY (Masahiro Yamamoto) is supported by the Research Program on Emerging and Re-emerging Infectious Diseases (JP19fk0108047), Japanese Initiative for Progress of Research on Infectious Diseases for global Epidemic (JP19fm0208018) and Strategic International Collaborative Research Program (19jm0210067h) from Agency for Medical Research and Development (AMED), Grant-in-Aid for Scientific Research on Innovative Areas (Production, function and structure of neo-self; 19H04809), for Scientific Research (B) (18KK0226 and 18H02642) and for Scientific Research (A) (19H00970) from Ministry of Education, Culture, Sports, Science and Technology of Japan.

\section{AUTHOR CONTRIBUTIONS}

EE and EM designed the experiments with the help of RP. EE, RP and EM wrote the manuscript. EE and RP performed the experiments with the help of $S B, P J B, A H, K S$ and MP. KC and OBS performed essential mass spectrometry run acquisitions and analysis. MY and $\mathrm{JCH}$ provided essential reagents to conduct the project.

\section{CONFLICT OF INTEREST}

Authors have no conflict of interest to declare. 


\section{Figures}

Figure 1: The IFN-inducible protein Irgm2 refrains non-canonical but not canonical inflammasome response

Otherwise specified, BMDMs were either infected with various gram-negative bacterial strains (MOI25) or stimulated with outer membrane vesicles (OMVs) for 16 hours.

(A) siRNA-treated BMDMs were infected for 16 hours with $S$. Typhimurium $\left(\operatorname{org} A^{-}\right)$and $\mathrm{LDH}$ and IL-1 $\beta$ release were measured.

(B) Cell death (LDH) and IL-1 $\beta$ release evaluation in WT, Irgm2 ${ }^{-1-}$, GBPChr3-/- and Casp11 $11^{-/}$BMDMs infected for 16 hours with different gram-negative bacteria (MOI 25).

(C) Western blot examination of processed caspase-1 (p20) and gasdermin-D (p30) in supernatants and pro-caspase-1 (p45), pro-gasdermin-D (p55) and GAPDH in cell lysates of WT and Irgm2-/- BMDMs infected for $16 \mathrm{~h}$ with different gram-negative bacterial strains. ${ }^{*}$ Non specific

(D) IL-1 $\beta$ and cell death (\% LDH) evaluation immortalized (i) BMDMs, WT, Irgm2 ${ }^{-1-}$,

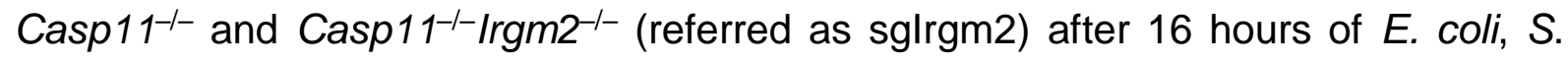
Typhimurium orgA- and OMV treatment.

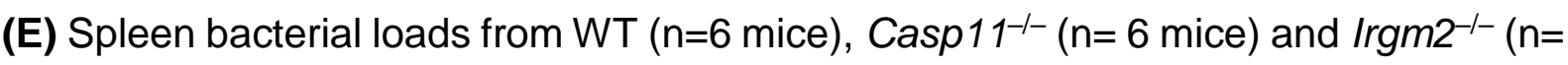
5 mice) intraperitoneally infected with $3.10^{5}$ S.Tm sif $A^{-}$for 48 hours.

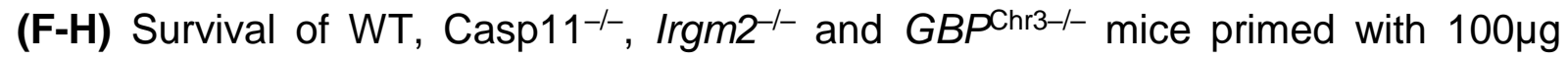
poly(l:C) for 6 hours and injected (i.p.) with $5 \mathrm{mg} / \mathrm{k}-1$ LPS or 5 and $25 \mu \mathrm{g}$ of OMVs $(\mathrm{n}=6$ animals per condition).

Data information: Data shown as means \pm SEM (Graphs A, B and D) from $n=4$ independent pooled experiments; ${ }^{*} p \leq 0.05$; ${ }^{* *} p \leq 0.01,{ }^{* * *} p \leq 0.001$ for the indicated comparisons using t-test with bonferroni correction. Image $(\mathrm{C})$ is representative of one experiment performed three times. $(E-H)$ are representative of three independent experiments; ${ }^{*} p \leq 0.05 ;{ }^{* *} p \leq 0.01,{ }^{* * *} p \leq 0.001$, Mann-Whitney analysis test (E) and log-rank Cox-Mantel test for survival comparisons $(\mathrm{F}-\mathrm{H})$. 

recruitment to intracellular bacteria.

743

Otherwise specified, BMDMs were treated with $2,5 \mu \mathrm{g} / 2.10^{5}$ cells of OMVs or infected with either $S$. Typhimurium $\operatorname{org} A^{-}\left(S\right.$.Tm $\left.\operatorname{org} A^{-}\right)$or $F$. tularensis spp novicida $(F$. novicida) with an $\mathrm{MOI}$ of 25 for various times.

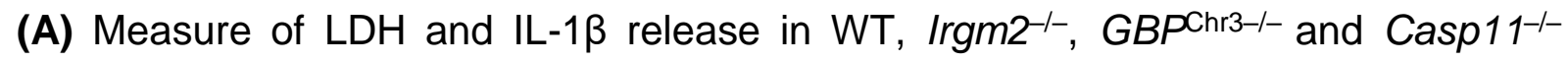
BMDMs were Irgm2 was knocked down 16 hours after exposure to $2,5 \mu \mathrm{g} / 2.10^{5}$ cells of OMVs.

(B) Cell death (LDH) and IL-1 $\beta$ release evaluation in Irgm2-silenced WT and GBPChr3I- BMDMs infected for 16 hours with either S.Tm orgA- or F. novicida (MOI 25).

(C) Florescence microscopy and associated quantifications of GBP-2 and -5 (green) recruitments to intracellular $S$. Tm orgA-mCherry (MOI 10, red) in IFNy-primed WT,

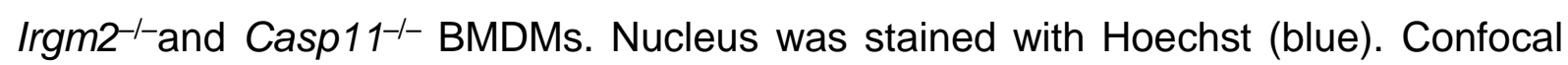
images shown are from one experiment and are representative of $n=3$ independent experiments; scale bars $5 \mu \mathrm{m}$. For quantifications, the percentage of GBP-associated bacteria was quantified; quantifications from $n=3$ independent experiments were then ploted and expressed as mean \pm SEM. ${ }^{* * *} p \leq 0.001$ for the indicated comparisons using t-test with bonferroni correction.

(D) Confocal fluorescence microscopy images and associated quantifications of caspase-11-C254G-GFP (green) recruitment to S.Tm-mCherry (orgA', red) in IFNyprimed iWT, ilrgm2-/- iGBPChr3-/- and iGBPChr3-/-Irgm2-/- BMDMs after 8 hours of infection. Nucleus (blue) was stained with Hoescht; scale bar $5 \mu \mathrm{m}$. For quantifications, the percentage of bacteria positive for caspase-11-C254G-GFP was determined by combining the bacterial counts from $n=3$ independent experiments and expressed as mean \pm SEM. ${ }^{* * *} p \leq 0.001$ for the indicated comparisons using t-test with bonferroni correction.

Data information: Data shown as means \pm SEM (Graphs A, B) from $n=4$ independent pooled experiments; ${ }^{*} p \leq 0.05 ;{ }^{* *} p \leq 0.01,{ }^{* * *} p \leq 0.001$ for the indicated comparisons using t-test with bonferroni correction. Images (C, D) are representative of one experiment performed three times. 

inflammasome activation.

774

(A) GFP-Trap coupled to mass spectrometry strategy used. The volcano plot represents 3 independent combined experiments. Threshold selection of enriched proteins in Irgm2-GFP fraction was set at 2 fold enrichment ( $x$ axis) and $p$-value $<0.05$ (y axis).

(B) GFP-Trap assay of the presence of Gate16 in Irgm2-GFP-enriched fraction from the lysates of IFNy-primed i/rgm2-/- BMDMs complemented with Irgm2-GFP or GFP. Gate16, Irgm2-GFP and GAPDH are shown in GFP-enriched fractions, flow-through and total cell lysates.

(C) $\mathrm{LDH}$ and IL-1 $\beta$ release from siRNA-treated WT BMDMs, and then exposed to 2.5 $\mu \mathrm{g} / 2.10^{5}$ cells of OMVs for 16 hours.

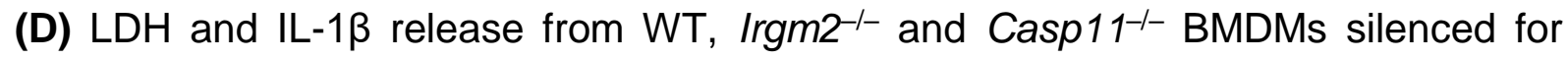
Gate 16 and treated for 16 hours with $2,5 \mu \mathrm{g} / 2.10^{5}$ cells of OMVs.

(E) Western blot examination of processed caspase-1 (p20) and gasdermin-D (p30) in supernatants and pro-caspase-1 (p45), pro-gasdermin-D (p55), Gate16 and GAPDH in cell lysates of Gate16-silenced WT, Irgm2-/- and GBPChr3-/- BMDMs exposed to $2,5.10^{5} \mu \mathrm{g} / 2.10^{5}$ cells of OMVs for 16 hours. * Non specific

(F) Representative confocal fluorescence microscopy images and associated quantifications of caspase-11-C254G-GFP (green) recruitment to S.Tm-mCherry $\left(\operatorname{org} A^{-}\right.$, red, MOI 10) in IFNy-primed iWT BMDMs silenced for Gate16 after 4 and 8 hours of infection. Nucleus (blue) was stained with Hoescht; scale bar $5 \mu \mathrm{m}$. For quantifications, the percentage of bacteria positive for caspase-11-C254G-GFP was determined by combining the bacterial counts from $n=3$ independent experiments and expressed as mean \pm SEM. ${ }^{* * *} p \leq 0.001$ for the indicated comparisons using t-test with bonferroni correction.

Data information: Data shown as means \pm SEM (Graphs C, D) from $n=4$ independent pooled experiments; ${ }^{* * *} p \leq 0.001$ for the indicated comparisons using t-test with bonferroni correction. Image $(B)$ is representative of one experiment performed two times and $(E)$ represents one experiment out of three. $(A)$ represents one experiment out of three independent experiments. 

macrophages.

(A) LDH and IL-1 $1 \beta$ release from siRNA-treated primary human Monocytes-Derived Macrophages (hMDMs) infected with $S$. Typhimurium orgA (MOI25) for 16 hours. When specified, the caspase-4/5 inhibitor Z-LEVD $(25 \mu \mathrm{M})$ or the NLRP3 inhibitor MCC950 $(10 \mu \mathrm{M})$ were added to the experiments. Results from $n=3$ donors were plotted.

(B) $\mathrm{LDH}$ and $\mathrm{LL}-1 \beta$ release from siRNA-treated primary human Monocytes-Derived Macrophages (hMDMs), primed with IFNy (10UI/mL) and PAM3CSK4 (100ng/mL) and then stimulated with Nigericin $(20 \mu \mathrm{M})$ for 4 hours. When specified, the caspase- $4 / 5$ inhibitor Z-LEVD $(25 \mu \mathrm{M})$ or the NLRP3 inhibitor MCC950 $(10 \mu \mathrm{M})$ were added to the experiments. Results from $\mathrm{n}=3$ donors were plotted.

Data information: Data shown as means \pm SEM (Graphs A, B) from $n=3$ independent donors; each donor is represented with a coloured circle; ${ }^{*} p \leq 0.05$, ${ }^{* *} p \leq 0.01$, ${ }^{* * *} p \leq$ correction. 


\section{Expanded Views (EV):}

\section{EV1: Irgm2 specifically controls non-canonical inflammasome response}

833

(A) qRT-PCR measurement of silencing efficacy on the mRNA levels of Irgm1-3, Gbp2 and Caspase-1 in BMDMs, prestimulated with $100 \mathrm{UI} / \mathrm{ml}$ of IFNy for 16 hours. $\mathrm{N}=3$ independent experiments normalized to $\beta$-actin mRNA levels. Data are expressed as mean \pm SEM.

(B) Immunoblotting of Irgm2, Caspase-1, Caspase-11 and GAPDH expression in IFNyprimed WT or Irgm2--- BMDMs. Image represents one experiment performed two times. * Non specific

(C) Immunoblotting of GBP2, GBP5 and GAPDH expression in LPS- or IFNy-primed WT or Irgm2 ${ }^{-1-}$ BMDMs. Image represents one experiment performed two times. * Non specific

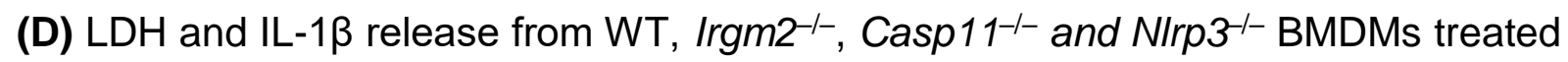
for 16 hours with $2,5 \mu \mathrm{g} / 2.10^{5}$ cells of OMVs in presence or not of $10 \mu \mathrm{M}$ of MCC950 (NLRP3 inhibitor). Data are expressed as mean \pm SEM from $n=4$ experiments.

(E) Immunoblots of Casp11 or Irgm2 deletion efficacy in immortalized BMDMs. Image represents one experiment performed two times. * Non specific

(F) Release of LDH and IL-1 $\beta$ from IFNy- and PAM3CSK4-primed WT, Irgm2-/-, Casp11 1-- or Casp1--Casp11--- BMDMs transfected (using FuGeneHD) with flagellin or poly $(\mathrm{dA}: \mathrm{dT})$ or stimulated with either Nigericin or TcdB toxin for 6 hours. Data are expressed as mean \pm SEM from $n=4$ experiments.

(G) Western blot examination of processed caspase-1 (p20) and gasdermin-D (p30) in supernatants and pro-caspase-1 (p45), pro-gasdermin-D (p55) and GAPDH in cell lysates of WT and Irgm2-/- BMDMs infected for $4 \mathrm{~h}$ with $S$. Typhimurium and $P$. aeruginosa (NLRC4 inflammasome). Image represents one experiment performed two times. * Non specific

(H) Cytokine levels in plasma from WT, Casp11 $1^{-/}$and $\operatorname{Irgm2}^{-/}$( $\mathrm{n}=6$ mice per condition) primed with $100 \mu \mathrm{g}$ poly(l:C) for 6 hours and injected i.p with $25 \mu \mathrm{g}$ of OMVs for 5 hours. Graphs represent one experiment out of three independent experiments; ${ }^{*} p \leq 0.05 ;{ }^{* *} p \leq 0.01,{ }^{* * *} p \leq 0.001$, Mann-Whitney analysis test. 
861

862

863

864

865

866

867

868

869

870

871

872

873

874

875

876

877

878

879

880

881

882

883

884

885

886

887

888

889

890

\section{EV2: Irgm2 deficiency drives GBP-independent caspase-11 targeting to gram-} negative bacterial membranes.

(A) Immunoblots of Irgm2 silencing efficacy in primary BMDMs. Image represents one experiment performed two times.

(B) Cell death (LDH) and IL-1 $\beta$ release evaluation in WT, GBPChr3-/-, Casp1 1 ${ }^{-1-}$ and Casp $^{-/-}$Casp 11 1-- BMDMs infected for 16 hours with either S.Tm orgA- or F. novicida (MOI 25). Data are expressed as mean \pm SEM from $n=4$ experiments.

(C) Immunoblots of Irgm2 deletion efficacy in immortalized GBPChr3-/-BMDMs. Image represents one experiment performed two times. * Non specific

(D) Kinetic of $S$. Tm $\left(\operatorname{org} A^{-}\right)$-induced cell death (\% LDH release) in IFNy-primed iWT, ilrgm2 $2^{--}$, i $G B P^{C h r 3-/-}$ and iGBPChr3-/-Irgm2-/- BMDMs. Data represent one experiment out of $n=3$ experiments and is expressed as mean \pm SEM

(E) Confocal fluorescence microscopy images and associated quantifications of caspase-11-C254G-GFP (green) recruitment to S.Tm-mCherry (orgA', red) in IFNy-

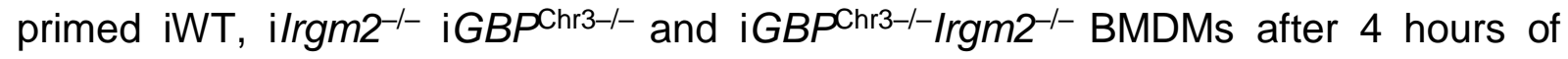
infection. Nucleus (blue) was stained with Hoescht; scale bar $5 \mu \mathrm{m}$. For quantifications, the percentage of bacteria positive for caspase-11-C254G-GFP was determined by combining the bacterial counts from $\mathrm{n}=3$ independent experiments and expressed as mean \pm SEM. ${ }^{* * *} p \leq 0$. for the indicated comparisons using t-test with bonferroni correction.

\section{EV 3: Gate-16 specifically inhibits the non-canonical inflammasome}

(A) Representation of top 11 enriched proteins isolated in Irgm2-GFP fraction. $\mathrm{N}=3$ independent experiments (Set1-3)

(B) qRT-PCR measurement of silencing efficacy on the mRNA levels of Gabarap, GabarapL1 and L2 (GATE16) in BMDMs, prestimulated with 100UI/ml of IFNy for 16 hours. $\mathrm{N}=3$ independent experiments normalized to $\beta$-actin mRNA levels. Data are expressed as mean \pm SEM.

(C) Immunoblots of GATE16 silencing efficacy in BMDMs. Image represents one experiment performed two times. * Non specific 
(D) Release of IL-1 $\beta$ from IFNy $(100 \mathrm{UI} / \mathrm{mL})$ and PAM3CSK4 $(100 \mathrm{ng} / \mathrm{mL})$-primed WT and $\mathrm{NIrp3}^{-1-}$ BMDMs treated with $20 \mu \mathrm{M}$ of Nigericin for 4 hours. Data are expressed as mean \pm SEM from $n=4$ experiments.

(E) Representative confocal fluorescence microscopy images and associated quantifications of caspase-11-C254G-GFP (green) recruitment to S.Tm-mCherry ( $\operatorname{org} A^{-}$, red, MOI 10) in IFNy-primed i/rgm2/- BMDMs silenced for Gate16 after 4 hours of infection. Nucleus (blue) was stained with Hoescht; scale bar $5 \mu \mathrm{m}$. For quantifications, the percentage of bacteria positive for caspase-11-C254G-GFP was determined by combining the bacterial counts from $n=3$ independent experiments and expressed as mean \pm SEM. ${ }^{* *} p \leq 0.001$ for the indicated comparisons using $t$-test with bonferroni correction.

\section{EV 4: Efficacy of hGATE16 silencing in monocyte-derived macrophages}

(A) qRT-PCR measurement of silencing efficacy on the mRNA levels of hGATE16 and IRGM in hMDMs, prestimulated with $10 \mathrm{UI} / \mathrm{ml}$ of IFNy for 8 hours. $\mathrm{N}=3$ independent experiments normalized to $\beta$-actin mRNA levels. Data are expressed as mean \pm SEM.

\section{Graphical abstract}

Caspase-11 target cytosolic Gram-negative bacterial LPS, which promotes pyroptosis and IL-1 cytokine maturation and release. IFN-inducible GTPases promote caspase11 enrichment on bacterial membranes. To the contrary, IFN-inducible Irgm2 and the non-canonical autophagy protein Gate-16 cooperate to refrain unnecessary caspase11 targeting to Gram-negative bacteria.

(1) 
920

921

922

923

924

925

926

927

928

929

930

931

932

933

934

935

936

937

938

939

940

941

942

943

944

945

946

947

948

949

950

951

\section{References}

Aachoui Y, Leaf IA, Hagar JA, Fontana MF, Campos CG, Zak DE, Tan MH, Cotter PA, Vance RE, Aderem A \& Miao EA (2013) Caspase-11 protects against bacteria that escape the vacuole. Science (80-. ). 339: 975-978

Aglietti RA, Estevez A, Gupta A, Ramirez MG, Liu PS, Kayagaki N, Ciferri C, Dixit VM \& Dueber EC (2016) GsdmD p30 elicited by caspase-11 during pyroptosis forms pores in membranes. Proc. Natl. Acad. Sci. U. S. A. 113: 7858-7863

Azzam KM, Madenspacher JH, Cain DW, Lai L, Gowdy KM, Rai P, Janardhan K, Clayton N, Cunningham W, Jensen H, Patel PS, Kearney JF, Taylor GA \& Fessler MB (2017) Irgm1 coordinately regulates autoimmunity and host defense at select mucosal surfaces. JCl insight 2:

Basters A, Knobeloch KP \& Fritz G (2018) USP18 - a multifunctional component in the interferon response. Biosci. Rep. 38:

Benaoudia S, Martin A, Puig Gamez M, Gay G, Lagrange B, Cornut M, Krasnykov K, Claude J, Bourgeois CF, Hughes S, Gillet B, Allatif O, Corbin A, Ricci R \& Henry T (2019) A genome-wide screen identifies IRF2 as a key regulator of caspase-4 in human cells. EMBO Rep. 20: e48235 Available at: http://www.ncbi.nlm.nih.gov/pubmed/31353801 [Accessed February 11, 2020]

Broz P, Ruby T, Belhocine K, Bouley DM, Kayagaki N, Dixit VM \& Monack DM (2012) Caspase-11 increases susceptibility to Salmonella infection in the absence of caspase1. Nature 490: 288-291

Cerqueira DM, Gomes MTR, Silva ALN, Rungue M, Assis NRG, Guimarães ES, Morais SB, Broz P, Zamboni DS \& C. Oliveira S (2018) Guanylate-binding protein 5 licenses caspase-11 for Gasdermin-D mediated host resistance to Brucella abortus infection. PLoS Pathog. 14: e1007519

Chen KW, Monteleone M, Boucher D, Sollberger G, Ramnath D, Condon ND, von Pein JB, Broz P, Sweet MJ \& Schroder K (2018) Noncanonical inflammasome signaling elicits gasdermin D-dependent neutrophil extracellular traps. Sci. Immunol. 3: Available at: http://www.ncbi.nlm.nih.gov/pubmed/30143554 [Accessed February 11, 2020]

Cheng KT, Xiong S, Ye Z, Hong Z, Di A, Tsang KM, Gao X, An S, Mittal M, Vogel SM, Miao EA, Rehman J \& Malik AB (2017) Caspase-11-mediated endothelial pyroptosis underlies endotoxemia-induced lung injury. J. Clin. Invest. 127: 4124-4135 
Choi YJ, Kim S, Choi Y, Nielsen TB, Yan J, Lu A, Ruan J, Lee HR, Wu H, Spellberg B \& Jung JU (2019) SERPINB1-mediated checkpoint of inflammatory caspase activation. Nat. Immunol. 20: 276-287

Coers J (2013) Self and Non-self Discrimination of Intracellular Membranes by the Innate Immune System. PLoS Pathog. 9:

Costa Franco MM, Marim F, Guimarães ES, Assis NRG, Cerqueira DM, Alves-Silva J, Harms J, Splitter G, Smith J, Kanneganti T-D, de Queiroz NMGP, Gutman D, Barber GN \& Oliveira SC (2018) Brucella abortus Triggers a cGAS-Independent STING Pathway To Induce Host Protection That Involves Guanylate-Binding Proteins and Inflammasome Activation . J. Immunol. 200: 607-622 Available at: http://www.ncbi.nlm.nih.gov/pubmed/29203515 [Accessed February 11, 2020]

Deng M, Tang Y, Li W, Wang X, Zhang R, Zhang X, Zhao X, Liu J, Tang C, Liu Z, Huang Y, Peng H, Xiao L, Tang D, Scott MJ, Wang Q, Liu J, Xiao X, Watkins S, Li J, et al (2018) The Endotoxin Delivery Protein HMGB1 Mediates Caspase-11-Dependent Lethality in Sepsis. Immunity 49: 740-753.e7 Available at: http://www.ncbi.nlm.nih.gov/pubmed/30314759 [Accessed February 11, 2020]

Feeley EM, Pilla-Moffett DM, Zwack EE, Piro AS, Finethy R, Kolb JP, Martinez J, Brodsky IE \& Coers J (2017) Galectin-3 directs antimicrobial guanylate binding proteins to vacuoles furnished with bacterial secretion systems. Proc. Natl. Acad. Sci. U. S. A. 114: E1698E1706

Finethy R, Jorgensen I, Haldar AK, De Zoete MR, Strowig T, Flavell RA, Yamamoto M, Nagarajan UM, Miao EA \& Coers J (2015) Guanylate binding proteins enable rapid activation of canonical and noncanonical inflammasomes in Chlamydia-infected macrophages. Infect. Immun. 83: 4740-4749 Available at: http://www.ncbi.nlm.nih.gov/pubmed/26416908 [Accessed February 11, 2020]

Finethy R, Luoma S, Orench-Rivera N, Feeley EM, Haldar AK, Yamamoto M, Kanneganti TD, Kuehn MJ \& Coers J (2017) Inflammasome Activation by Bacterial Outer Membrane Vesicles Requires Guanylate Binding Proteins. MBio 8: Available at: http://www.ncbi.nlm.nih.gov/pubmed/28974614 [Accessed February 11, 2020]

Fink MP (2014) Animal models of sepsis. Virulence 5: 143-153

Fisch D, Bando H, Clough B, Hornung V, Yamamoto M, Shenoy AR \& Frickel E (2019) Human GBP 1 is a microbe-specific gatekeeper of macrophage apoptosis and pyroptosis . EMBO J. 38: e100926 Available at: 
http://www.ncbi.nlm.nih.gov/pubmed/31268602 [Accessed February 11, 2020]

986

987

988

989

990

991

992

993

994

995

996

997

998

999

1000

1001

1002

1003

1004

1005

1006

1007

1008

1009

1010

1011

1012

1013

1014

1015

1016

1017

Green R, Ireton RC \& Gale M (2018) Interferon-stimulated genes: new platforms and computational approaches. Mamm. Genome 29: 593-602 Available at:

http://www.ncbi.nlm.nih.gov/pubmed/29982912 [Accessed February 11, 2020]

Gu Y, Princely Abudu Y, Kumar S, Bissa B, Choi SW, Jia J, Lazarou M, Eskelinen E, Johansen T \& Deretic V (2019) Mammalian Atg8 proteins regulate lysosome and autolysosome biogenesis through $<\operatorname{scp}>S N A R E</ \operatorname{scp}>$ s. EMBO J. 38: Available at: https://onlinelibrary.wiley.com/doi/abs/10.15252/embj.2019101994 [Accessed February $11,2020]$

Hagar JA, Powell DA, Aachoui Y, Ernst RK \& Miao EA (2013) Cytoplasmic LPS activates caspase-11: Implications in TLR4-independent endotoxic shock. Science (80-. ). 341: $1250-1253$

Haldar AK, Foltz C, Finethy R, Piro AS, Feeley EM, Pilla-Moffett DM, Komatsu M, Frickel EM \& Coers J (2015) Ubiquitin systems mark pathogen-containing vacuoles as targets for host defense by guanylate binding proteins. Proc. Natl. Acad. Sci. U. S. A. 112: E5628E5637

Haldar AK, Saka HA, Piro AS, Da Dunn J, Henry SC, Taylor GA, Frickel EM, Valdivia RH \& Coers J (2013) IRG and GBP Host Resistance Factors Target Aberrant, 'Non-self' Vacuoles Characterized by the Missing of 'Self' IRGM Proteins. PLoS Pathog. 9: e1003414 Available at: http://www.ncbi.nlm.nih.gov/pubmed/23785284 [Accessed February 11, 2020]

Hayward JA, Mathur A, Ngo C \& Man SM (2018) Cytosolic Recognition of Microbes and Pathogens: Inflammasomes in Action. Microbiol. Mol. Biol. Rev. 82: Available at: http://www.ncbi.nlm.nih.gov/pubmed/30209070 [Accessed February 11, 2020]

Kayagaki N, Lee BL, Stowe IB, Kornfeld OS, O'Rourke K, Mirrashidi KM, Haley B, Watanabe C, Roose-Girma M, Modrusan Z, Kummerfeld S, Reja R, Zhang Y, Cho V, Daniel Andrews T, Morris LX, Goodnow CC, Bertram EM \& Dixit VM (2019) IRF2 transcriptionally induces GSDMD expression for pyroptosis. Sci. Signal. 12: Available at: http://www.ncbi.nlm.nih.gov/pubmed/31113851 [Accessed February 11, 2020]

Kayagaki N, Stowe IB, Lee BL, O'Rourke K, Anderson K, Warming S, Cuellar T, Haley B, Roose-Girma M, Phung QT, Liu PS, Lill JR, Li H, Wu J, Kummerfeld S, Zhang J, Lee WP, Snipas SJ, Salvesen GS, Morris LX, et al (2015) Caspase-11 cleaves gasdermin D for non-canonical inflammasome signalling. Nature 526: 666-671 Available at: 
http://www.ncbi.nlm.nih.gov/pubmed/26375259 [Accessed February 11, 2020]

1019

1020

1021

1022

1023

1024

1025

1026

1027

1028

1029

1030

1031

1032

1033

1034

1035

1036

1037

1038

1039

1040

1041

1042

1043

1044

1045

1046

1047

1048

1049

1050

Kayagaki N, Warming S, Lamkanfi M, Walle L Vande, Louie S, Dong J, Newton K, Qu Y, Liu J, Heldens S, Zhang J, Lee WP, Roose-Girma M \& Dixit VM (2011) Non-canonical inflammasome activation targets caspase-11. Nature 479: 117-121

Kayagaki N, Wong MT, Stowe IB, Ramani SR, Gonzalez LC, Akashi-takamura S, Miyake K, Zhang J, Lee WP, Forsberg LS, Carlson RW \& Dixit VM (2013) Independent of TLR4. Science (80-. ). 130: 1246-1249

Kim BH, Shenoy AR, Kumar P, Bradfield CJ \& MacMicking JD (2012) IFN-inducible GTPases in host cell defense. Cell Host Microbe 12: 432-444

Kim S, Eun H \& Jo E-K (2019) Roles of Autophagy-Related Genes in the Pathogenesis of Inflammatory Bowel Disease. Cells 8: 77 Available at: http://www.ncbi.nlm.nih.gov/pubmed/30669622 [Accessed February 11, 2020]

Lagrange B, Benaoudia S, Wallet P, Magnotti F, Provost A, Michal F, Martin A, Di Lorenzo F, Py BF, Molinaro A \& Henry T (2018) Human caspase-4 detects tetra-acylated LPS and cytosolic Francisella and functions differently from murine caspase-11. Nat. Commun. 9: 242 Available at: http://www.ncbi.nlm.nih.gov/pubmed/29339744 [Accessed February 11, 2020]

Latz E, Visintin A, Lien E, Fitzgerald KA, Monks BG, Kurt-Jones EA, Golenbock DT \& Espevik T (2002) Lipopolysaccharide rapidly traffics to and from the golgi apparatus with the toll-like receptor 4-MD-2-CD14 complex in a process that is distinct from the initiation of signal transduction. J. Biol. Chem. 277: 47834-47843

Lee BL, Stowe IB, Gupta A, Kornfeld OS, Roose-Girma M, Anderson K, Warming S, Zhang J, Lee WP \& Kayagaki N (2018) Caspase-11 auto-proteolysis is crucial for noncanonical inflammasome activation. J. Exp. Med. 215: 2279-2288

Lee YK \& Lee JA (2016) Role of the mammalian ATG8/LC3 family in autophagy: Differential and compensatory roles in the spatiotemporal regulation of autophagy. BMB Rep. 49: 424-430

Li P, Allen H, Banerjee S, Franklin S, Herzog L, Johnston C, McDowell J, Paskind M, Rodman L, Salfeld J, Towne E, Tracey D, Wardwell S, Wei FY, Wong W, Kamen R \& Seshadri T (1995) Mice deficient in IL-1 $\beta$-converting enzyme are defective in production of mature IL-1 $\beta$ and resistant to endotoxic shock. Cell 80: 401-411

Liau NPD, Laktyushin A, Lucet IS, Murphy JM, Yao S, Whitlock E, Callaghan K, Nicola NA, Kershaw NJ \& Babon JJ (2018) The molecular basis of JAK/STAT inhibition by SOCS1. 


\section{Nat. Commun. 9: 1-14}

Liu BC, Sarhan J, Panda A, Muendlein HI, llyukha V, Coers J, Yamamoto M, Isberg RR \& Poltorak A (2018) Constitutive Interferon Maintains GBP Expression Required for Release of Bacterial Components Upstream of Pyroptosis and Anti-DNA Responses. Cell Rep. 24: 155-168.e5 Available at: http://www.ncbi.nlm.nih.gov/pubmed/29972777 [Accessed February 11, 2020]

Liu X, Zhang Z, Ruan J, Pan Y, Magupalli VG, Wu H \& Lieberman J (2016) Inflammasomeactivated gasdermin $D$ causes pyroptosis by forming membrane pores. Nature 535: 153-158

Man SM, Karki R, Malireddi RKS, Neale G, Vogel P, Yamamoto M, Lamkanfi M \& Kanneganti TD (2015) The transcription factor IRF1 and guanylate-binding proteins target activation of the AIM2 inflammasome by Francisella infection. Nat. Immunol. 16: 467-475 Available at: http://www.ncbi.nlm.nih.gov/pubmed/25774715 [Accessed February 11, 2020]

Man SM, Karki R, Sasai M, Place DE, Kesavardhana S, Temirov J, Frase S, Zhu Q, Malireddi RKS, Kuriakose T, Peters JL, Neale G, Brown SA, Yamamoto M \& Kanneganti TD (2016) IRGB10 Liberates Bacterial Ligands for Sensing by the AIM2 and Caspase-11-NLRP3 Inflammasomes. Cell 167: 382-396.e17 Available at: http://www.ncbi.nlm.nih.gov/pubmed/27693356 [Accessed February 11, 2020]

Maric-Biresev J, Hunn JP, Krut O, Helms JB, Martens S \& Howard JC (2016) Loss of the interferon- $\gamma$-inducible regulatory immunity-related GTPase (IRG), Irgm1, causes activation of effector IRG proteins on lysosomes, damaging lysosomal function and predicting the dramatic susceptibility of Irgm1-deficient mice to infection. BMC Biol. 14: 33 Available at: http://bmcbiol.biomedcentral.com/articles/10.1186/s12915-016-0255-4 [Accessed February 11, 2020]

Martinon F, Pétrilli V, Mayor A, Tardivel A \& Tschopp J (2006) Gout-associated uric acid crystals activate the NALP3 inflammasome. Nature 440: 237-241

Mehto S, Chauhan S, Jena KK, Chauhan NR, Nath P, Sahu R, Dhar K, Das SK \& Chauhan $S$ (2019a) IRGM restrains NLRP3 inflammasome activation by mediating its SQSTM1/p62-dependent selective autophagy. Autophagy 15: 1645-1647

Mehto S, Jena KK, Nath P, Chauhan S, Kolapalli SP, Das SK, Sahoo PK, Jain A, Taylor GA \& Chauhan S (2019b) The Crohn's Disease Risk Factor IRGM Limits NLRP3 Inflammasome Activation by Impeding Its Assembly and by Mediating Its Selective 
Autophagy. Mol. Cell 73: 429-445.e7 Available at:

http://www.ncbi.nlm.nih.gov/pubmed/30612879 [Accessed February 11, 2020]

Meunier E, Dick MS, Dreier RF, Schürmann N, Broz DK, Warming S, Roose-Girma M, Bumann D, Kayagaki N, Takeda K, Yamamoto M \& Broz P (2014) Caspase-11 activation requires lysis of pathogen-containing vacuoles by IFN-induced GTPases. Nature 509: 366-370

Meunier E, Wallet P, Dreier RF, Costanzo S, Anton L, Rühl S, Dussurgey S, Dick MS, Kistner A, Rigard M, Degrandi D, Pfeffer K, Yamamoto M, Henry T \& Broz P (2015) Guanylate-binding proteins promote activation of the AIM2 inflammasome during infection with Francisella novicida. Nat. Immunol. 16: 476-484 Available at: http://www.ncbi.nlm.nih.gov/pubmed/25774716 [Accessed February 11, 2020]

Napier BA, Brubaker SW, Sweeney TE, Monette P, Rothmeier GH, Gertsvolf NA, Puschnik A, Carette JE, Khatri P \& Monack DM (2016) Complement pathway amplifies caspase11-dependent cell death and endotoxin-induced sepsis severity. J. Exp. Med. 213: 2365-2382 Available at: http://www.ncbi.nlm.nih.gov/pubmed/27697835 [Accessed February 11, 2020]

Nguyen TN, Padman BS, Usher J, Oorschot V, Ramm G \& Lazarou M (2016) Atg8 family LC3/GAB ARAP proteins are crucial for autophagosome-lysosome fusion but not autophagosome formation during PINK1/Parkin mitophagy and starvation. J. Cell Biol. 215: 857-874

Park S, Choi J, Biering SB, Dominici E, Williams LE \& Hwang S (2016) Targeting by AutophaGy proteins (TAG): Targeting of IFNG-inducible GTPases to membranes by the LC3 conjugation system of autophagy. Autophagy 12: 1153-1167 Available at: https://www.tandfonline.com/doi/full/10.1080/15548627.2016.1178447 [Accessed February 11, 2020]

pei chunying, wang chun \& xu hongwei (2017) Irgm1 suppresses NLRP3 Inflammasomemediated IL-1 $\beta$ production. J. Immunol. 198:

Pilla-Moffett D, Barber MF, Taylor GA \& Coers J (2016) Interferon-Inducible GTPases in Host Resistance, Inflammation and Disease. J. Mol. Biol. 428: 3495-3513 Available at: http://www.ncbi.nlm.nih.gov/pubmed/27181197 [Accessed February 11, 2020]

Pilla DM, Hagar JA, Haldar AK, Mason AK, Degrandi D, Pfeffer K, Ernst RK, Yamamoto M, Miao EA \& Coers J (2014) Guanylate binding proteins promote caspase-11-dependent pyroptosis in response to cytoplasmic LPS. Proc. Natl. Acad. Sci. U. S. A. 111: 6046- 
6051 Available at: http://www.ncbi.nlm.nih.gov/pubmed/24715728 [Accessed February 11, 2020]

Rathinam VAK, Zhao Y \& Shao F (2019) Innate immunity to intracellular LPS. Nat. Immunol. 20: 527-533 Available at: http://www.ncbi.nlm.nih.gov/pubmed/30962589 [Accessed February 11, 2020]

Rühl S \& Broz P (2015) Caspase-11 activates a canonical NLRP3 inflammasome by promoting K+ efflux. Eur. J. Immunol. 45: 2927-2936 Available at: http://www.ncbi.nlm.nih.gov/pubmed/26173909 [Accessed February 11, 2020]

Rühl S, Shkarina K, Demarco B, Heilig R, Santos JC \& Broz P (2018) ESCRT-dependent membrane repair negatively regulates pyroptosis downstream of GSDMD activation. Science (80-. ). 362: 956-960

Sagiv $Y$ (2000) GATE-16, a membrane transport modulator, interacts with NSF and the Golgi v-SNARE GOS-28. EMBO J. 19: 1494-1504

Santos JC, Dick MS, Lagrange B, Degrandi D, Pfeffer K, Yamamoto M, Meunier E, Pelczar P, Henry T \& Broz P (2018) LPS targets host guanylate-binding proteins to the bacterial outer membrane for non-canonical inflammasome activation . EMBO J. 37: Available at: http://www.ncbi.nlm.nih.gov/pubmed/29459437 [Accessed February 11, 2020]

Sasai M, Sakaguchi N, Ma JS, Nakamura S, Kawabata T, Bando H, Lee Y, Saitoh T, Akira S, Iwasaki A, Standley DM, Yoshimori T \& Yamamoto M (2017) Essential role for GABARAP autophagy proteins in interferon-inducible GTPase-mediated host defense. Nat. Immunol. 18: 899-910 Available at: http://www.ncbi.nlm.nih.gov/pubmed/28604719 [Accessed February 11, 2020]

Sborgi L, Rühl S, Mulvihill E, Pipercevic J, Heilig R, Stahlberg H, Farady CJ, Müller DJ, Broz $P$ \& Hiller S (2016) GSDMD membrane pore formation constitutes the mechanism of pyroptotic cell death . EMBO J. 35: 1766-1778 Available at: http://emboj.embopress.org/lookup/doi/10.15252/embj.201694696\%5Cnpapers3://public ation/doi/10.15252/embj.201694696 [Accessed February 11, 2020]

Schmid-Burgk JL, Gaidt MM, Schmidt T, Ebert TS, Bartok E \& Hornung V (2015) Caspase-4 mediates non-canonical activation of the NLRP3 inflammasome in human myeloid cells. Eur. J. Immunol. 45: 2911-2917 Available at: http://www.ncbi.nlm.nih.gov/pubmed/26174085 [Accessed February 11, 2020] Cleavage of GSDMD by inflammatory caspases determines pyroptotic cell death. 
Nature 526: 660-665

1151

1152

1153

1154

1155

1156

1157

1158

1159

1160

1161

1162

1163

1164

1165

1166

1167

1168

1169

1170

1171

1172

1173

1174

1175

1176

1177

1178

1179

1180

1181

1182

Thieblemont N \& Wright SD (1999) Transport of bacterial lipopolysaccharide to the Golgi apparatus. J. Exp. Med. 190: 523-534

Thurston TLM, Matthews SA, Jennings E, Alix E, Shao F, Shenoy AR, Birrell MA \& Holden DW (2016) Growth inhibition of cytosolic Salmonella by caspase-1 and caspase-11 precedes host cell death. Nat. Commun. 7: 1-15

Vanaja SK, Russo AJ, Behl B, Banerjee I, Yankova M, Deshmukh SD \& Rathinam VAK (2016) Bacterial Outer Membrane Vesicles Mediate Cytosolic Localization of LPS and Caspase-11 Activation. Cell 165: 1106-1119

Wallet P, Benaoudia S, Mosnier A, Lagrange B, Martin A, Lindgren H, Golovliov I, Michal F, Basso P, Djebali S, Provost A, Allatif O, Meunier E, Broz P, Yamamoto M, Py BF, Faudry E, Sjöstedt A \& Henry T (2017) IFN-y extends the immune functions of Guanylate Binding Proteins to inflammasome-independent antibacterial activities during Francisella novicida infection. PLoS Pathog. 13: e1006630 Available at: http://www.ncbi.nlm.nih.gov/pubmed/28968459 [Accessed February 11, 2020]

Wang S, Miura M, Jung YK, Zhu H, Li E \& Yuan J (1998) Murine caspase-11, an ICEinteracting protease, is essential for the activation of ICE. Cell 92: 501-509

Yamamoto M, Okuyama M, Ma JS, Kimura T, Kamiyama N, Saiga H, Ohshima J, Sasai M, Kayama H, Okamoto T, Huang DCS, Soldati-Favre D, Horie K, Takeda J \& Takeda K (2012) A cluster of interferon- $y$-inducible $p 65$ gtpases plays a critical role in host defense against toxoplasma gondii. Immunity 37: 302-313 Available at: http://www.ncbi.nlm.nih.gov/pubmed/22795875 [Accessed February 11, 2020]

Yang J, Zhao Y \& Shao F (2015) Non-canonical activation of inflammatory caspases by cytosolic LPS in innate immunity. Curr. Opin. Immunol. 32: 78-83 Available at: http://www.ncbi.nlm.nih.gov/pubmed/25621708 [Accessed February 11, 2020]

Yang X, Cheng X, Tang Y, Qiu X, Wang Y, Kang H, Wu J, Wang Z, Liu Y, Chen F, Xiao X, Mackman N, Billiar TR, Han J \& Lu B (2019) Bacterial Endotoxin Activates the Coagulation Cascade through Gasdermin D-Dependent Phosphatidylserine Exposure. Immunity 51: 983-996.e6

Zhao YO, Könen-Waisman S, Taylor GA, Martens S \& Howard JC (2010) Localisation and mislocalisation of the interferon-inducible immunity-related GTPase, Irgm1 (LRG-47) in mouse cells. PLoS One 5:

Zwack EE, Feeley EM, Burton AR, Hu B, Yamamoto M, Kanneganti TD, Bliska JB, Coers J \& 
bioRxiv preprint doi: https://doi. org/10.1101/2020.03 06 980433. this version posted March 8,2020 . The copyright holder for this preprint (which was not certified by peer review) is the author/funder, who has granted bioRxiv a license to display the preprint in perpetuity. It is made available under aCC-BY-NC-ND 4.0 International license.

Brodsky IE (2017) Guanylate binding proteins regulate inflammasome activation in response to hyperinjected Yersinia translocon components. Infect. Immun. 85: Available 

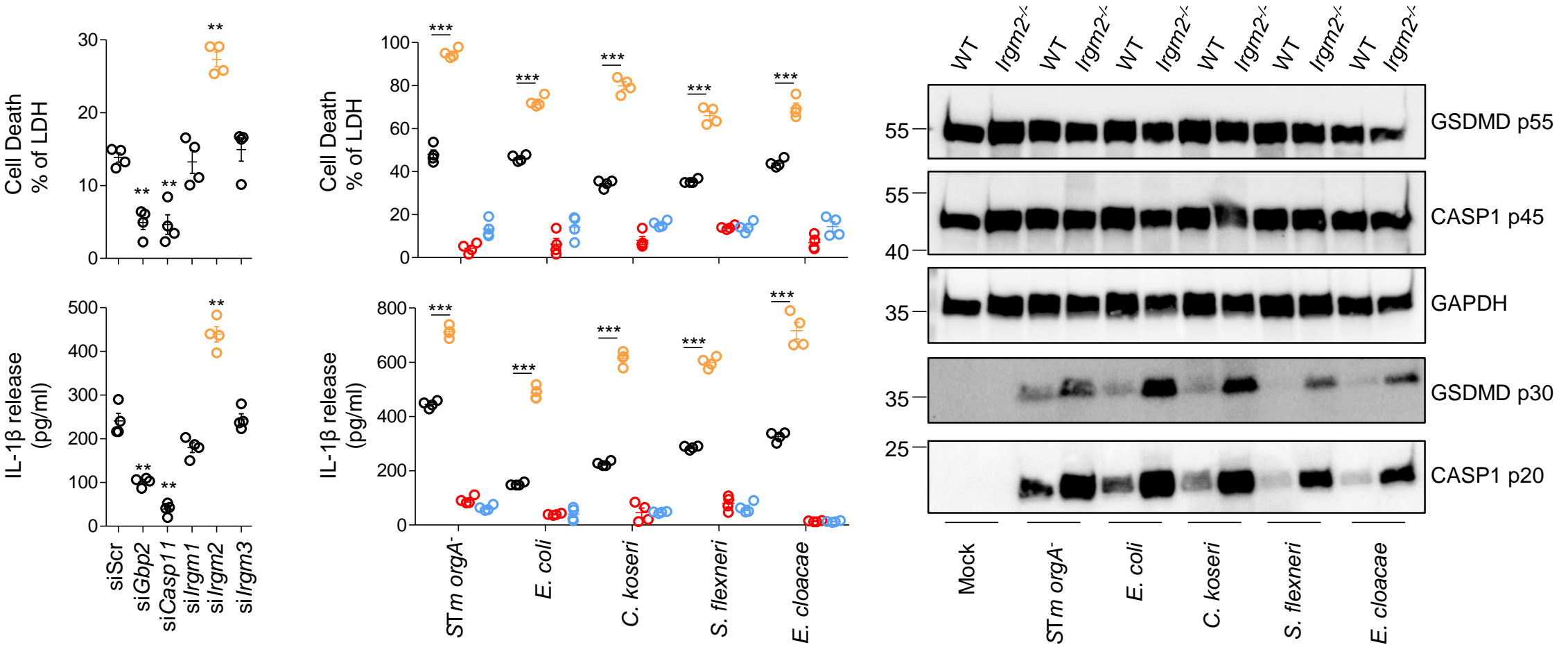

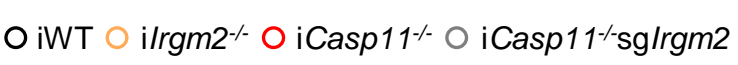
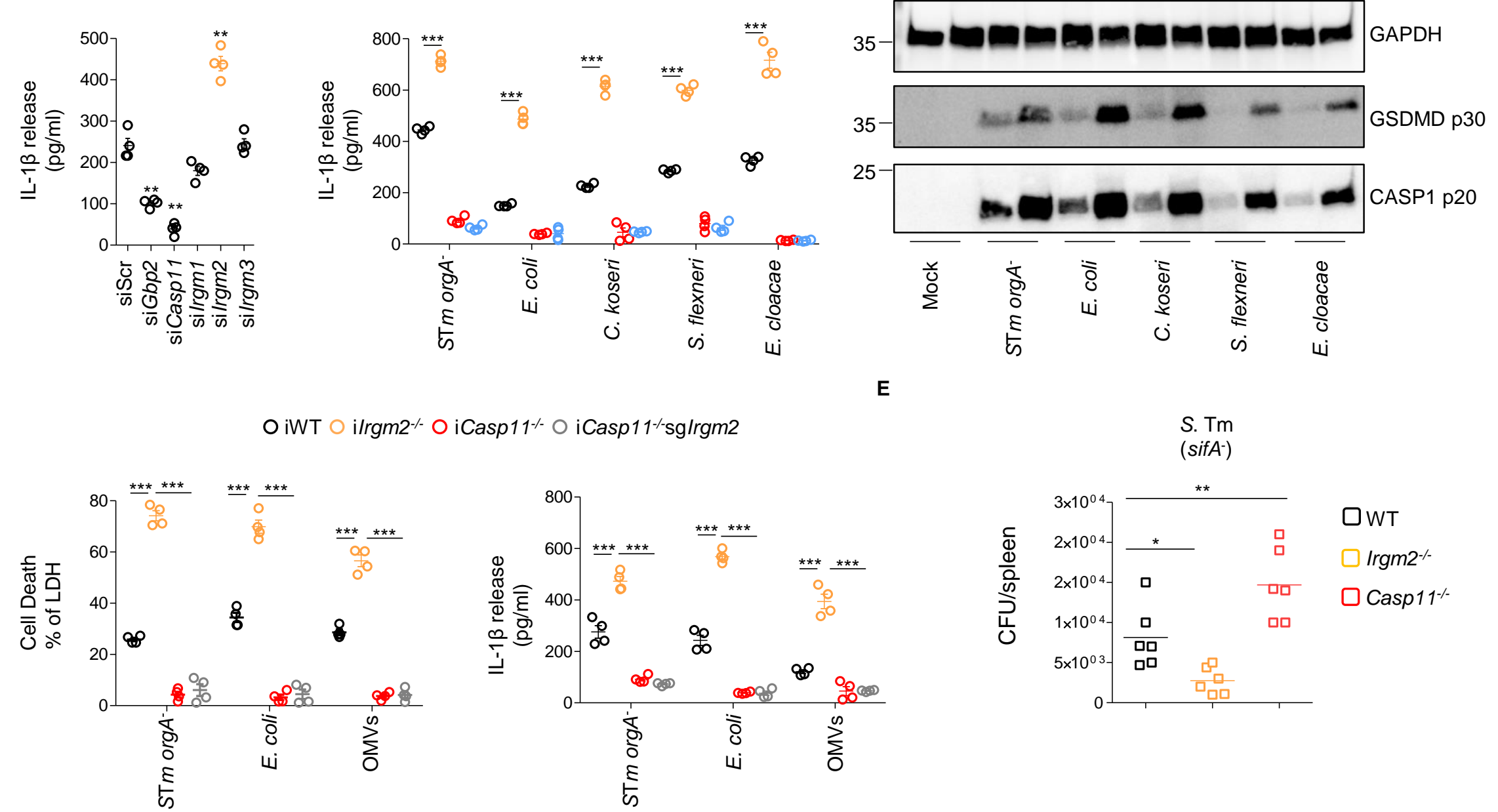

G
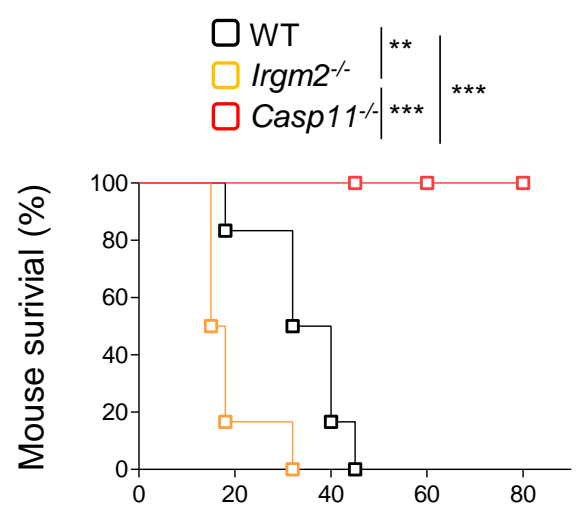

LPS injection $5 \mathrm{mg} \cdot \mathrm{kg}^{-1}$

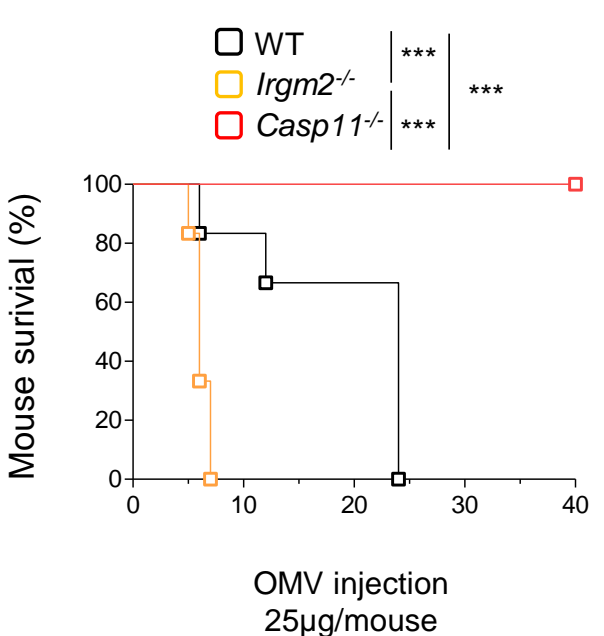

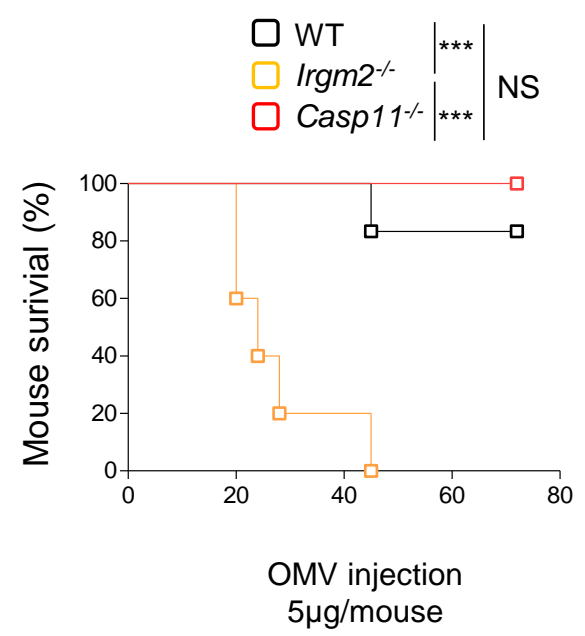




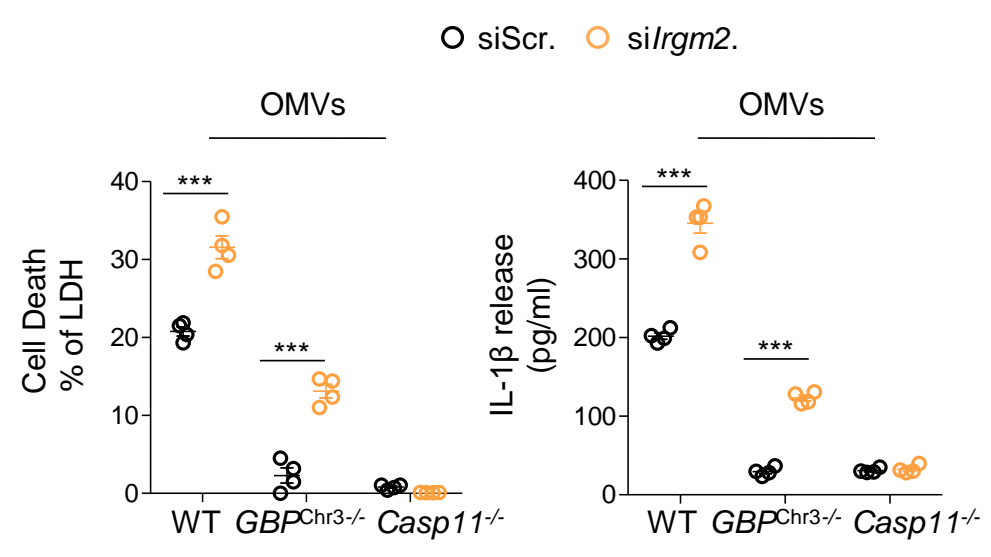

O WT O GBPChr3-/

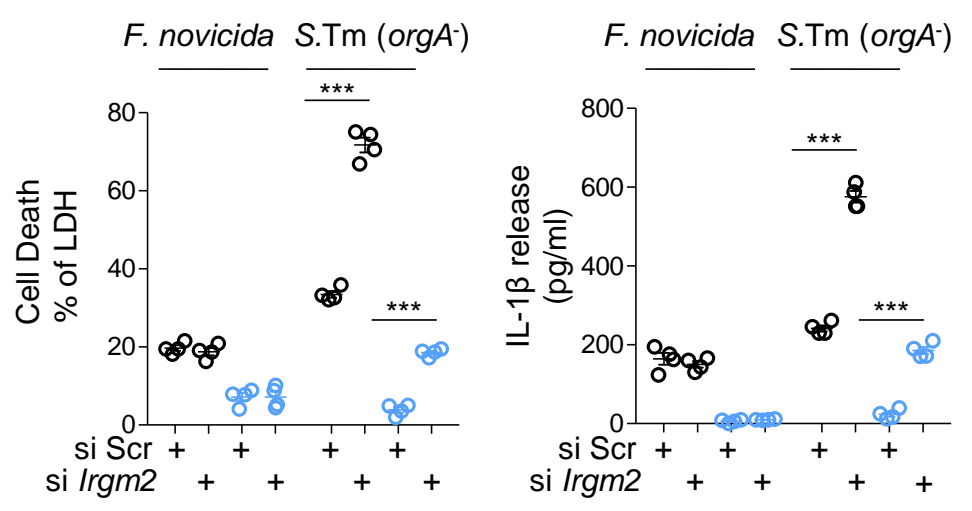

C
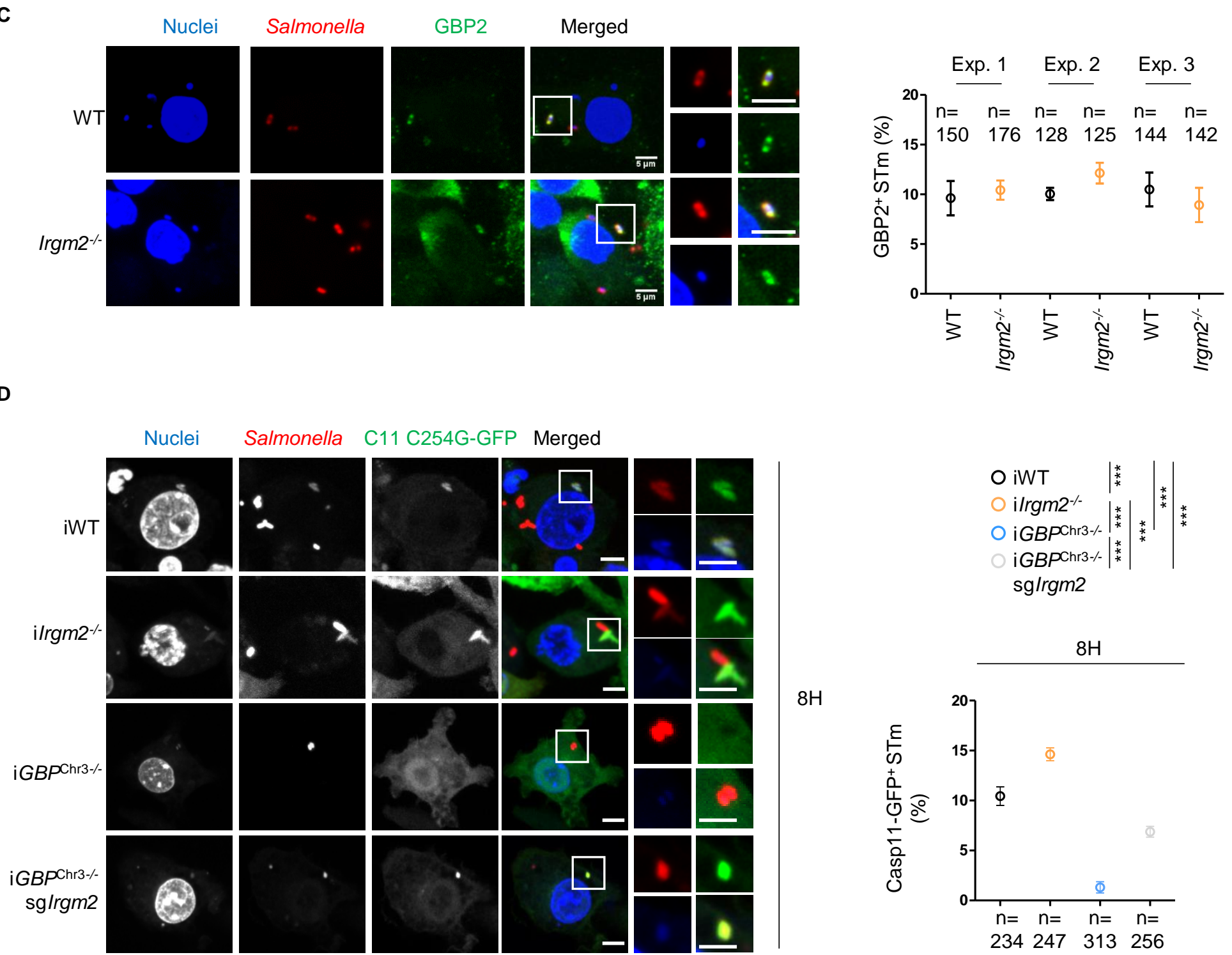

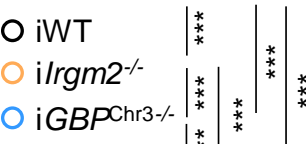

iGBPChr3- $\mid \frac{*}{*}$

sg/rgm2

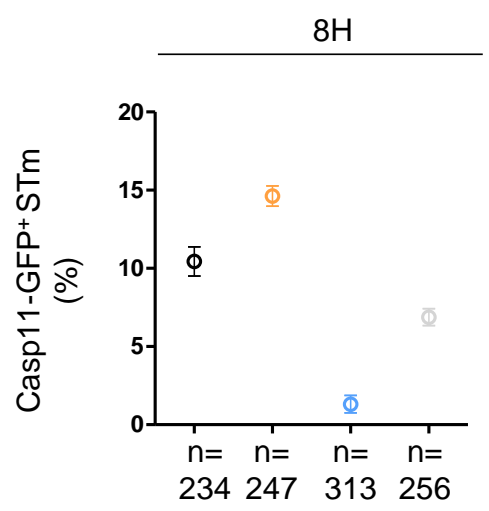




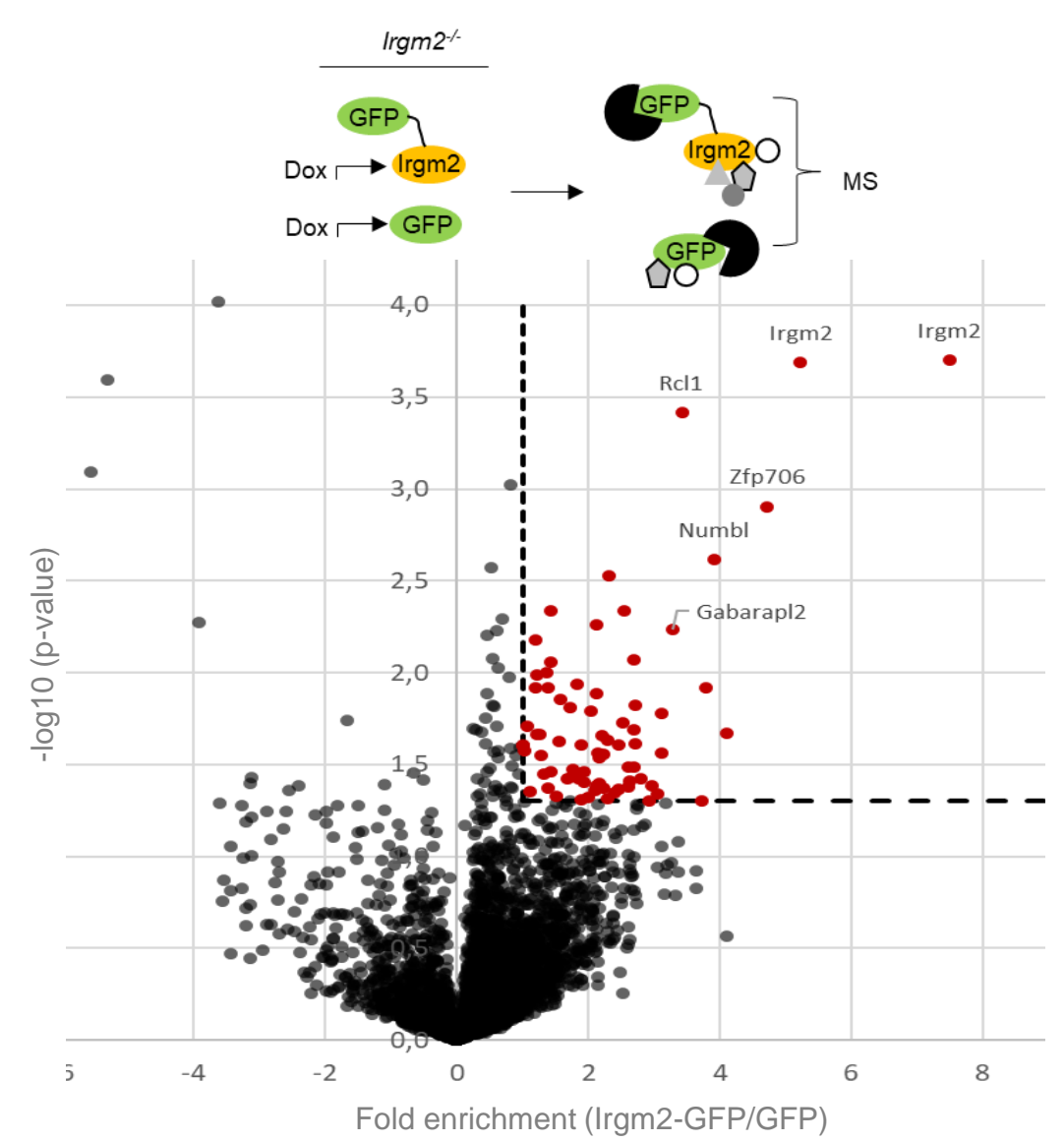

$\begin{array}{ll}\text { O siScr } & \text { siGabarapL1 } \\ \text { O siGabarap } & \text { o siGabarapL2 }\end{array}$
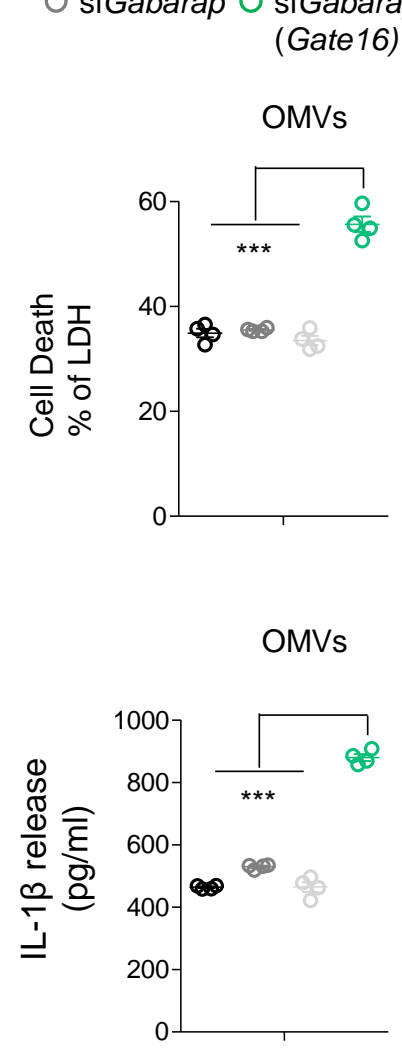

\begin{abstract}
D
\end{abstract}
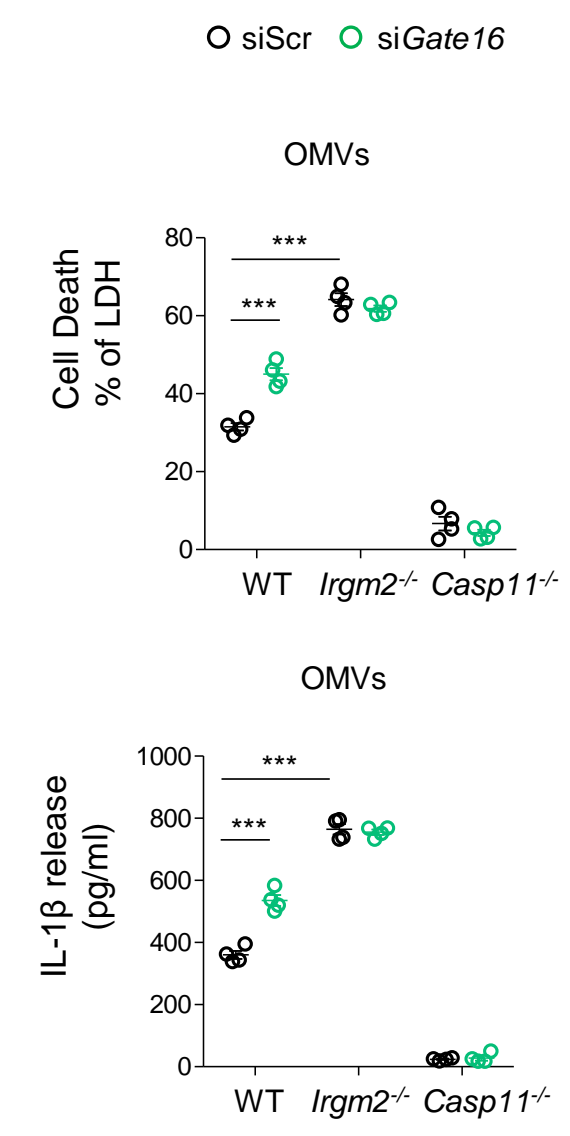

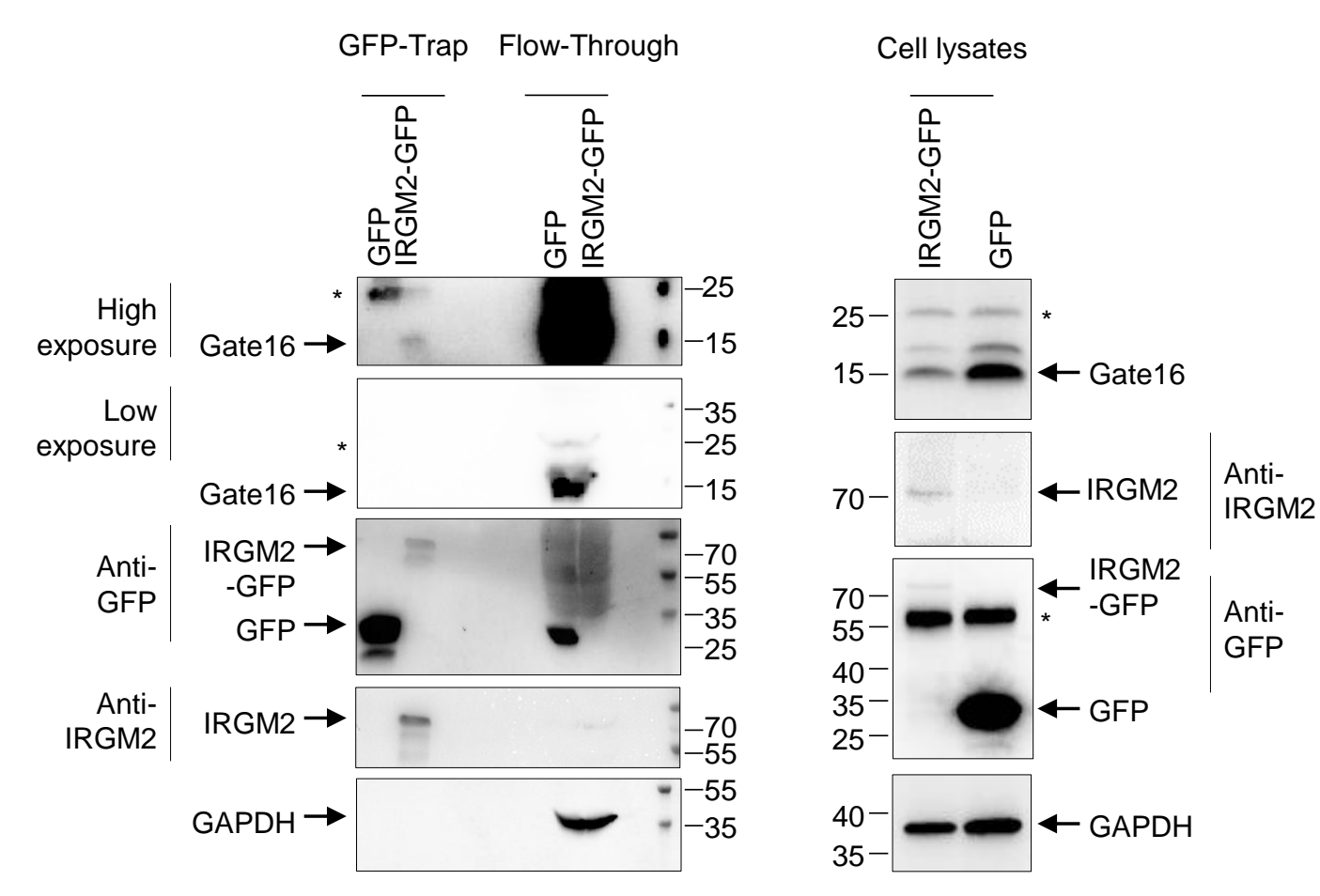

E

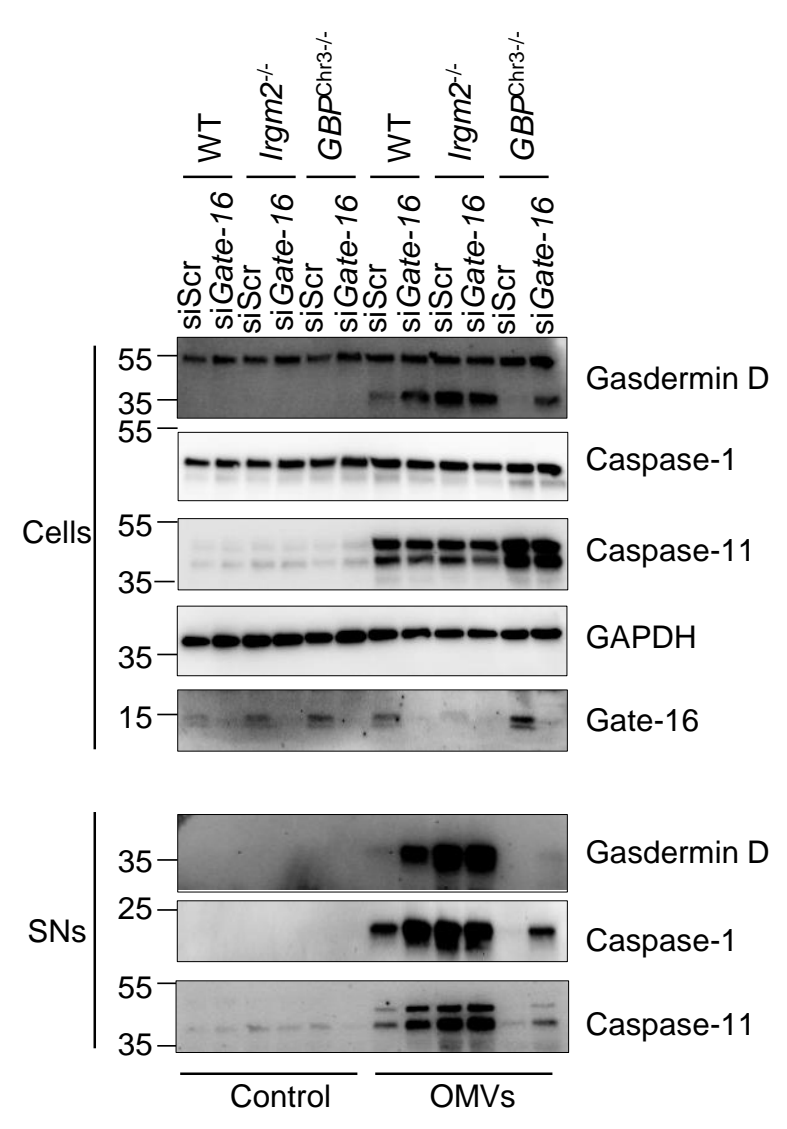




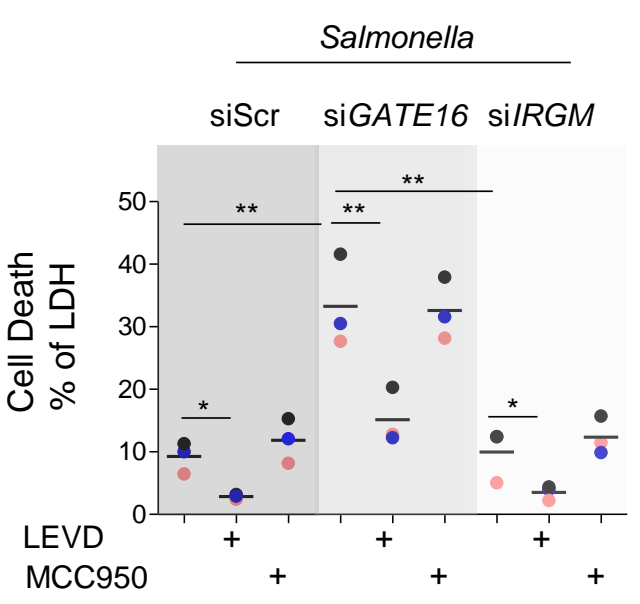

siScr SiGATE16 silRGM
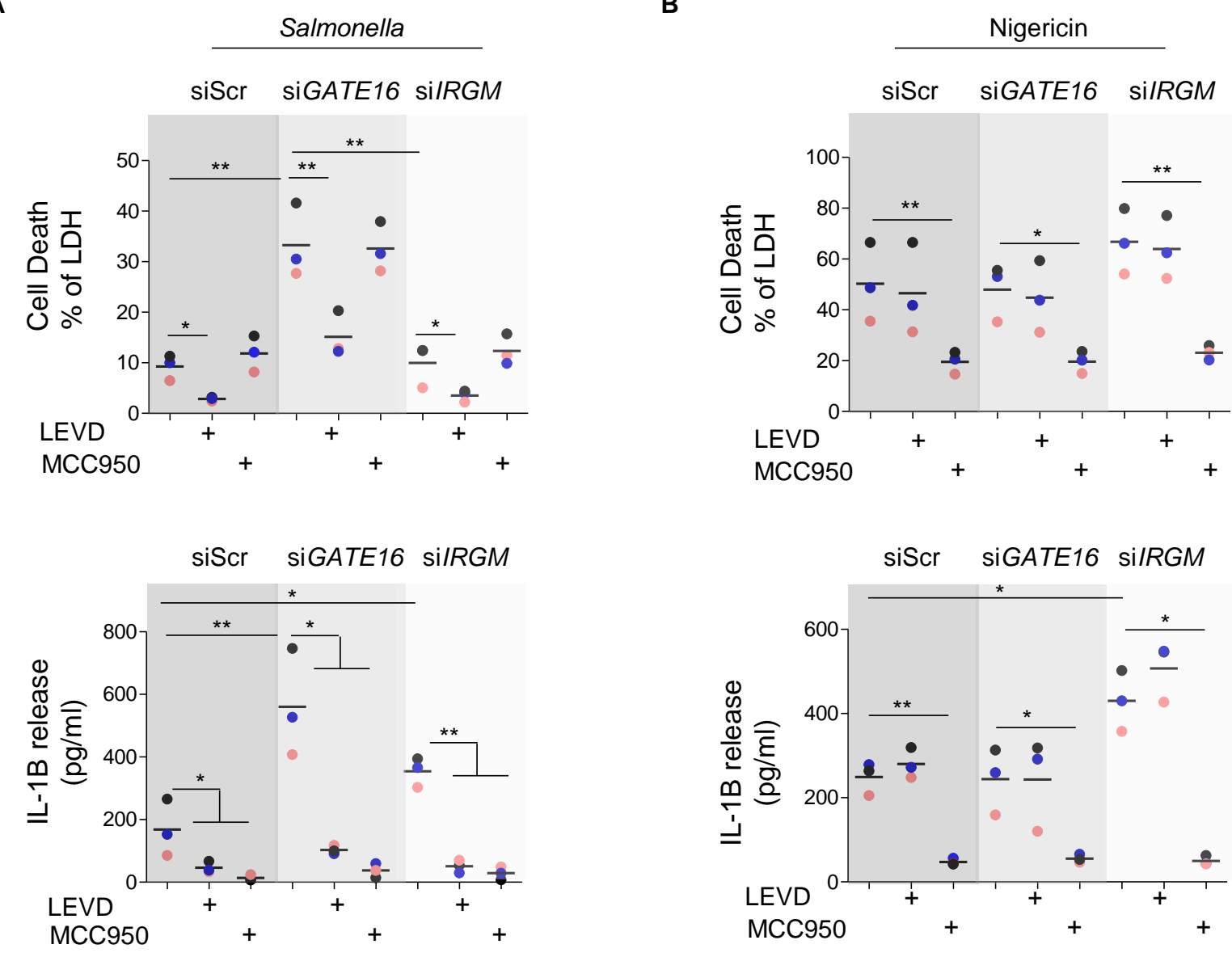